\title{
Analysis of the Deformation Characteristics of the Surrounding Rock Mass a Deep Tunnel during Excavation through a Fracture Zone
}

\author{
Junhong Huang \\ Wuhan University of Technology \\ Guang Zhang \\ Wuhan University of Technology \\ Yi Luo ( $\nabla 1964927081 @ q q . c o m$ ) \\ Wuhan University of Technology \\ Shaohua Hu \\ Wuhan University of Technology \\ Hangli Gong \\ Wuhan University of Technology \\ Xinping Li \\ Wuhan University of Technology \\ Xin Liu \\ Wuhan University of Technology
}

\section{Research Article}

Keywords: deeptunnel, fracture zone, rock excavation, surrounding rock deformation,excavation footage

Posted Date: February 15th, 2021

DOI: https://doi.org/10.21203/rs.3.rs-192629/v1

License: (c) (1) This work is licensed under a Creative Commons Attribution 4.0 International License.

Read Full License 


\title{
Analysis of the deformation characteristics of the surrounding rock
} mass a deep tunnel during excavation through a fracture zone

\author{
Junhong Huang ${ }^{1,2,3}$, Guang Zhang ${ }^{1}$, Yi Luo ${ }^{2 *}$, Shaohua Hu${ }^{1}$, Hangli Gong ${ }^{2,3}$, Xinping Li $^{2}$, Xin Liu ${ }^{2,3}$ \\ 1 School of Safety Science and Emergency Management, Wuhan University of Technology, Wuhan, China; \\ 2 Hubei Key Laboratory of Road-bridge and Structure Engineering, Wuhan University of Technology, Wuhan \\ China; \\ 3 School of Civil Engineering and Architecture, Wuhan University of Technology, Wuhan, China; \\ *Corresponding author: Yi Luo, E-mail address: 1964927081@qq.com.
}

Abstract: Aiming at geological disasters triggered by fracture zones in surrounding rocks during the excavation of deep railway tunnels, the research investigated deformation and failure of surrounding rocks triggered by sudden changes of rock quality encountered in a tunnel excavation project. The research started from analysis of a field case: the Daliang Tunnel on the Gansu-Qinghai section of the Lanzhou-Urumuqi second double-track railway in China. The deformation profiles of surrounding rocks at different distances from the fracture zone was evaluated. The deformation of surrounding rocks in and around the fracture zone was studied by combining in-situ measurement, theoretical research, and numerical simulation. In addition, relationships of deformation of surrounding rocks in the section of the fracture zone with the materials and length of advanced support as well as the excavation footage behind the fracture zone were discussed. Analysis of the results showed that there is an inflection point on the deformation curves of surrounding rocks far ahead of the fracture zone; however, it is difficult to observe the inflection point on deformation curves of surrounding rocks in engineering practice as the rocks there have undergone substantial deformation before being exposed. A combination of material properties and length of advanced support is conducive to controlling the deformation of surrounding rocks in the fracture zone. Taking a rate of deformation of surrounding rocks in the fracture zone as less than $0.1 \mathrm{~mm} / \mathrm{d}$ as the stability criterion, the excavated length of that rock mass behind the zone at a footage of $1 \mathrm{~m} / \mathrm{d}$ is about two thirds of that at $2 \mathrm{~m} / \mathrm{d}$ and half of that at 3 $\mathrm{m} / \mathrm{d}$ when the deformation stabilizes.

Keywords: deep tunnel, fracture zone, rock excavation, surrounding rock deformation, excavation footage. 


\section{Introduction}

With the vigorous development of infrastructure in China in recent years, tunnels running through mountains need to be built for highways and railways. In the context, it has become a general trend for future cavern excavation to form underground tunnels by fully-mechanised construction ${ }^{[1]}$, in which the full-face excavation is key, whereas, it has become increasingly common to encounter adverse geological conditions such as fault fracture zones during tunnel construction. Owing to being characterised by low strength, ease of deformation due to looseness, and poor self-stabilisation capacity ${ }^{[2-4]}$, these fracture zones pose a great threat to the safety and long-term stability of underground tunnel construction projects ${ }^{[5]}$. Considering this, the stress state on the section of the fracture zone must be understood before excavating to this position. Using the finite element method, Zeng et al. ${ }^{[6]}$ and Zhou et al. ${ }^{[7]}$ simulated the full-face excavation and support process when tunnelling through a fault fracture zone. In addition, they analysed the stress redistribution within the surrounding rock after full-face excavation. Moussaei et al. ${ }^{[8]}$ designed and constructed a set of physical models to simulate the full-face excavation process of a circular tunnel and the volume loss and change induced by the excavation. Using a continuous cross-section monitoring system, Li et al. ${ }^{[9]}$ monitored the convergence of a tunnel, to avoid excessive deformations thereof triggering a collapse.

If disasters such as collapses, rockbursts, and water in-rush occur in the surrounding rocks during the fully-mechanised, full-face excavation in the section of the fracture zone, the tunnel boring machine (TBM) may be deformed upon extrusion, becoming jammed, and even damaged $[10,11]$. All these problems are caused by the large deformation after excavation unloading of the fracture zone, making it necessary to study the deformation of the rock mass in the fracture zone under conditions involving excavation disturbance. Zheng et al. ${ }^{[12]}$ and Ortlepp et al. ${ }^{[13]}$ state that excavation unloading using the TBM breaks the stress equilibrium state and subsequent stress redistribution may lead to the cracking, grooving, spalling, and collapse of rocks on the excavation face or tunnel walls. Lu et al. ${ }^{[14]}$ analysed the stability of surrounding rocks in a fault fracture zone and investigated the changes in, and distribution of, surface and deep displacement of surrounding rocks. Chen et al. ${ }^{[15]}$ explored the extrusion and failure mechanisms of a deep tunnel constructed in broken carbonaceous phyllite under high geostatic stresses. Through theoretical analysis and numerical simulation, Zhan et al. ${ }^{[16]}$ conducted multi-factor coupling analysis on the 
failure mechanism of soft-rock roadways, considering a convergence trend in all directions of high rheology and large deformation as the essential feature of the deformation of deep soft-rock roadways. Under the effects of fluid-mechanical coupling, Wang et al. ${ }^{[17]}$, Ding et al. ${ }^{[18]}$, and Barla ${ }^{[19]}$ conducted triaxial unloading mechanical tests on sandstone at different initial confining pressures and unloading rates. In this way, they studied the evolution of the energy in sandstone specimens during damage induced by unloading and discussed the influences of the initial confining pressure and rate of unloading on the deformation of sandstone.

Scholars have conducted much research into means of controlling the deformation of, and damage to surrounding rocks in the fracture zone ${ }^{[20,21]}$. Aiming at control over deformation of surrounding rocks in deep underground caverns, Xie et al. ${ }^{[22]}$ proposed a set of comprehensive treatment methods and elaborated a support mechanism based on the unloading of the rock surrounding such caverns. This enriches the theory and technology behind control of the deformation of surrounding rocks of deep roadways. By combining the finite element and discrete element methods, Huo et al. ${ }^{[23]}$, Su et al. ${ }^{[24]}$, and Huang et al. ${ }^{[25]}$ studied the deformation and failure mechanisms of surrounding rocks of caverns and proposed corresponding techniques with which to control the surrounding rock. To solve problems pertaining to the support of deep roadways under high geostress and in the presence of fracture zones, Li et al. ${ }^{[26]}$ studied the deformation of roadways and modes of failure of supporting structures. On this basis, they proposed a new support scheme combining multi-level anchorage and concrete filled steel tubes. By constructing tunnel models containing a regional fracture zone, Xie et al. ${ }^{[27]}$ and Cheng et al. ${ }^{[28]}$ simulated and analysed the excavation, to determine an optimal support scheme for the rock surrounding the tunnel and provide a basis for in-situ construction. Lyu et al. ${ }^{[29]}$ studied the strengthening effect of full-face anchorage on a roadway constructed in thick, soft, rock, and transformed the longitudinal confinement effect of the excavation face to the circumferential virtual internal support force for the first time. In this way, they proposed a two-dimensional (2-d) model for the full-face anchorage of the roadway constructed in thick, soft, rock. Du et al. ${ }^{[30]}$ built a mechanical model for the boundary curves of plastic zones and the distribution of the principal stress of surrounding rocks of a circular tunnel under the effect of non-tectonic stress. By analysing the influences of different factors on the shapes of plastic zones and principal stress in the surrounding rock, they believed that stability of the rock surrounding a circular tunnel can be 
improved by a series of measures. These include inhibiting the harmful expansion of plastic zones, improving the principal stress regime, and allowing uniform distribution of plastic zones within the range controllable by the support system.

Taking excavation of the fracture zone in the Daliang Tunnel in China as the engineering background, the present research investigated the method for predicting the fracture zone according to the deformation of the rock surrounding the tunnel. Moreover, the control effects of the length and material properties of advanced support on deformation of surrounding rocks in, and around, the fracture zone were also studied, and the severity of the damage to the excavation footage and length of the tunnel behind the fracture zone to regional support structures in the fracture zone was investigated. Finally, the appropriate length and material properties of advanced support as well as excavation footage and length of the tunnel behind the fracture zone were determined.

\section{Practical problems during excavation through the fracture zone in the Daliang Tunnel}

\subsection{Project background}

Table 1 Classification of surrounding rocks and designed excavation methods of the Daliang Tunnel [31]

\begin{tabular}{lcc}
\hline Starting and ending mileage & Surrounding rocks & Geological features \\
\hline DK328+820 $\sim$ DK329+810 & V & Gravel soil, Stone, Joint fissure development \\
DK329+810 $\sim$ DK330+130 & IV & Sandstone slate, Joint development, Rock fragmentation \\
DK330+130 $\sim$ DK330+700 & III & Sandstone slate, Good lithology \\
DK330+700 $\sim$ DK330+980 & IV & Sandstone slate, Joint development, Rock fragmentation \\
DK330+980 D DK331+440 & III & Sandstone slate, Good lithology \\
DK331+440 $\sim$ DK332+040 & IV & Sandstone slate, Joint fissure development \\
DK332+040 $\sim$ DK334+790 & III & Limestone slate, Large buried depth, Good lithology \\
DK334+790 DK334+840 & IV & F5 fault influence zone, Limestone slate, Fracture development \\
DK334+840 DK335+040 & V & F5 fault fracture zone, Fault hornstone \\
DK335+040 D DK335+370 & V & Affected by structure, Rock fragmentation \\
\hline
\end{tabular}
Lanzhou-Urumuqi second double-track railway in China is in Menyuan County, Qinghai Province. 
This is a mid to high-mountain area in Qilian Mountains with an average elevation of 3600 to $4200 \mathrm{~m}$ (4430 $\mathrm{m}$ at its peak). From chainage DK328+820 to DK335+370, the tunnel has a total

111 length of $6550 \mathrm{~m}$ and runs through sandstone, limestone, slate, and the F5 fault fracture zone. The 112 classification and geological features of surrounding rocks in different mileage ranges are listed in 113 Table 1.

\section{$114 \quad 2.2$ Excavation process and analysis of monitoring data}

When excavating the tunnel to DK334+241, a collapse occurred at a position 24 to $34 \mathrm{~m}$ from the tunnel face, and the specific location is shown in Fig. 1. The steel frame for primary support fell off under compression and about $185 \mathrm{~m}^{3}$ of broken loose rocks became destabilised and collapsed into the tunnel. The resulting collapse cavity was $3.5 \mathrm{~m}$ deep, $6 \mathrm{~m}$ high, and $7 \mathrm{~m}$ long (Fig. 2). Surrounding rocks in the collapse zone contained fragmented carbonaceous slate interlayers and were significantly affected by the tectonic action. They collapsed constantly and were in a state of failure. Within the $10 \mathrm{~m}$ around the collapse zone, the primary shotcrete of surrounding rocks was found to contain numerous cracks, shotcrete on the vault showed severe spalling, and the maximum convergence of the sidewalls reached $1 \mathrm{~m}$. The monitoring and measurement of the surrounding rocks showed that their collapse led to large deformations in and around that location. At $5 \mathrm{~m}$ from the collapse zone, the subsidence and convergence on the day of collapse reached $36.4 \mathrm{~mm}$ and $57.6 \mathrm{~mm}$, respectively.

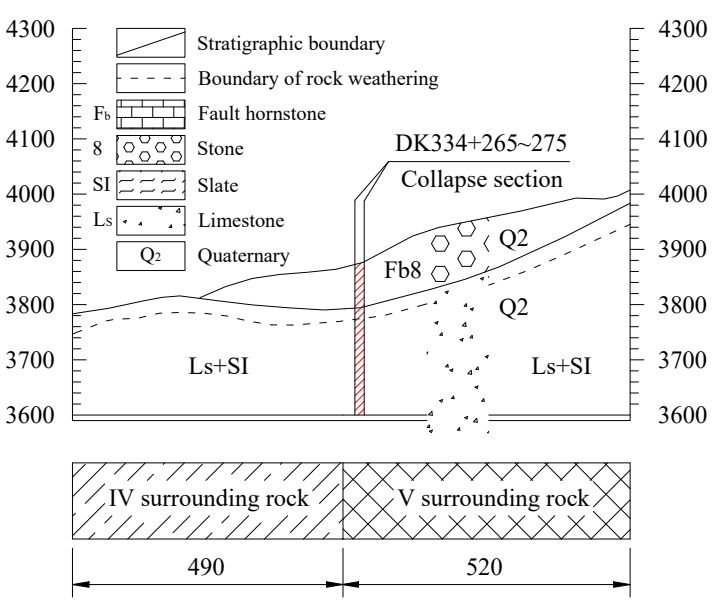

Fig. 1 The longitudinal profile of the collapse zone in the Daliang Tunnel (unit: $\mathrm{m}$ )

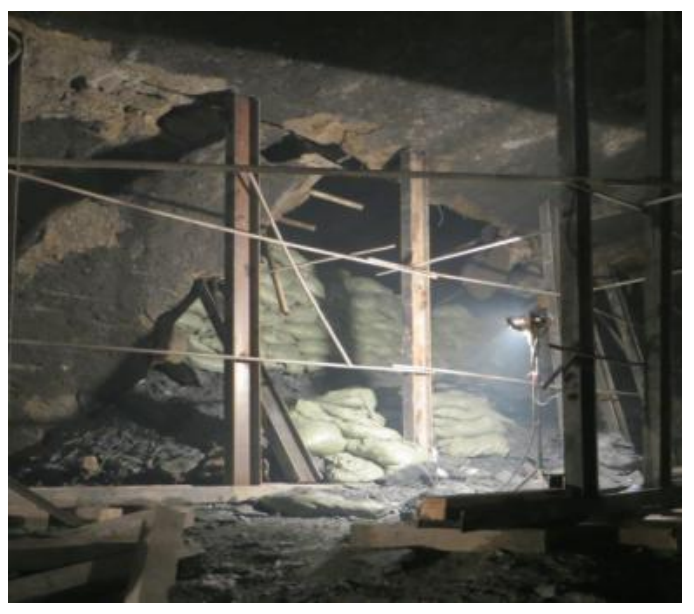

Fig. 2 Collapse of the fracture zone 

section and the zone around were observed (Fig. 3). It was found that the cumulative deformation 130 of surrounding rocks in the section was far larger than that in the surrounding zone, and even 131 larger than that in other excavated tunnel sections and locations that had been monitored over a longer time. Therefore, accurately judging types of surrounding rocks ahead and identifying the potential fracture zone is of important practical significance when selecting a rational excavation scheme, implementing advanced support measures, and actively controlling deformation and stabilizing the surrounding rock.

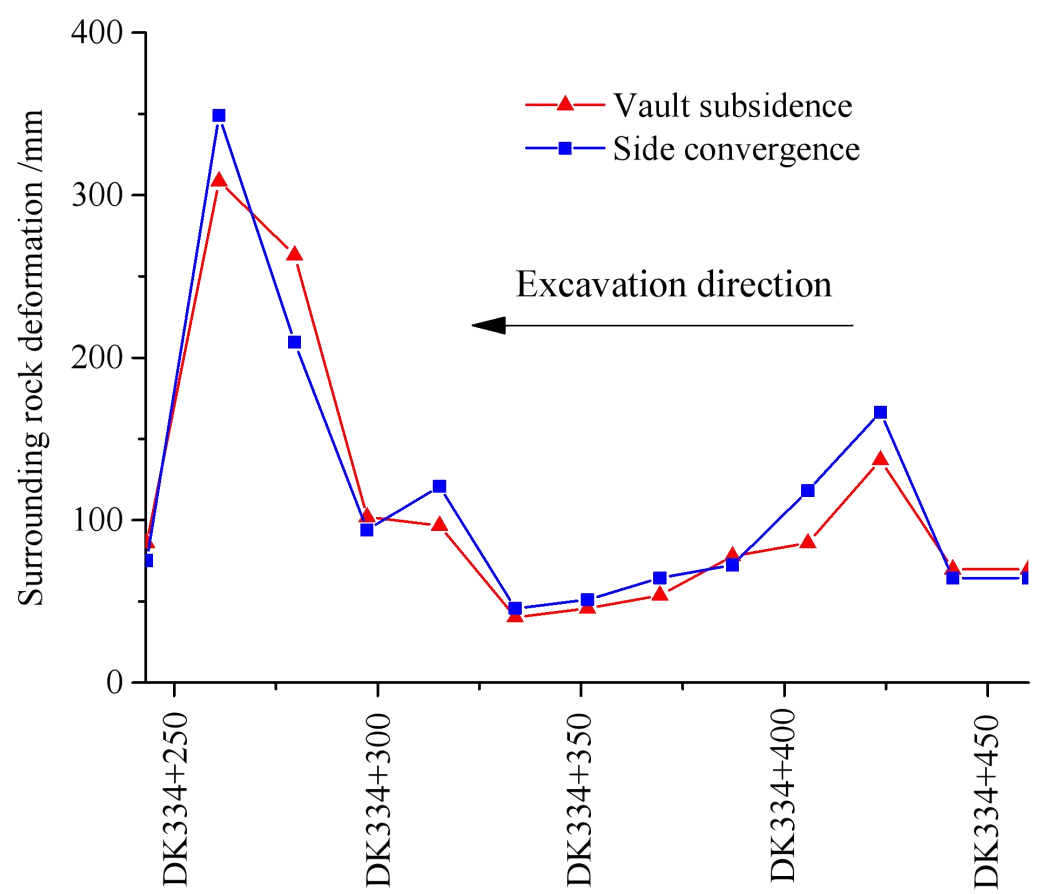

Fig. 3 Monitoring results of cumulative deformation during the excavation

It remains difficult to identify small fracture zones or areas of suddenly-changing quality of surrounding rocks in the design stage due to difficulty in exploration and the high cost incurred; besides, the geological forecast can only explore a limited area in a single time, is costly, and even disturbs the normal field excavation process, therefore, it is impractical to completely rely on the geological forecast to judge whether a small fracture zone lies ahead or not. The deformation profiles of homogeneous rocks generally show a certain regularity, while the presence of a fracture zone influences the deformation characteristics of surrounding rocks within a certain distance, that is, characteristics of deformation curves of surrounding rocks, to some extent, can reflect changes in the nature of the surrounding rocks ahead. 

the quality of surrounding rocks and without fracture zones around were analyzed. Relationships between the monitoring data and cumulative subsidence at monitoring points at different positions are plotted (Fig. 4), there is an inflection point on the curve fitted between the cumulative subsidence of the vault and number of days of monitoring.

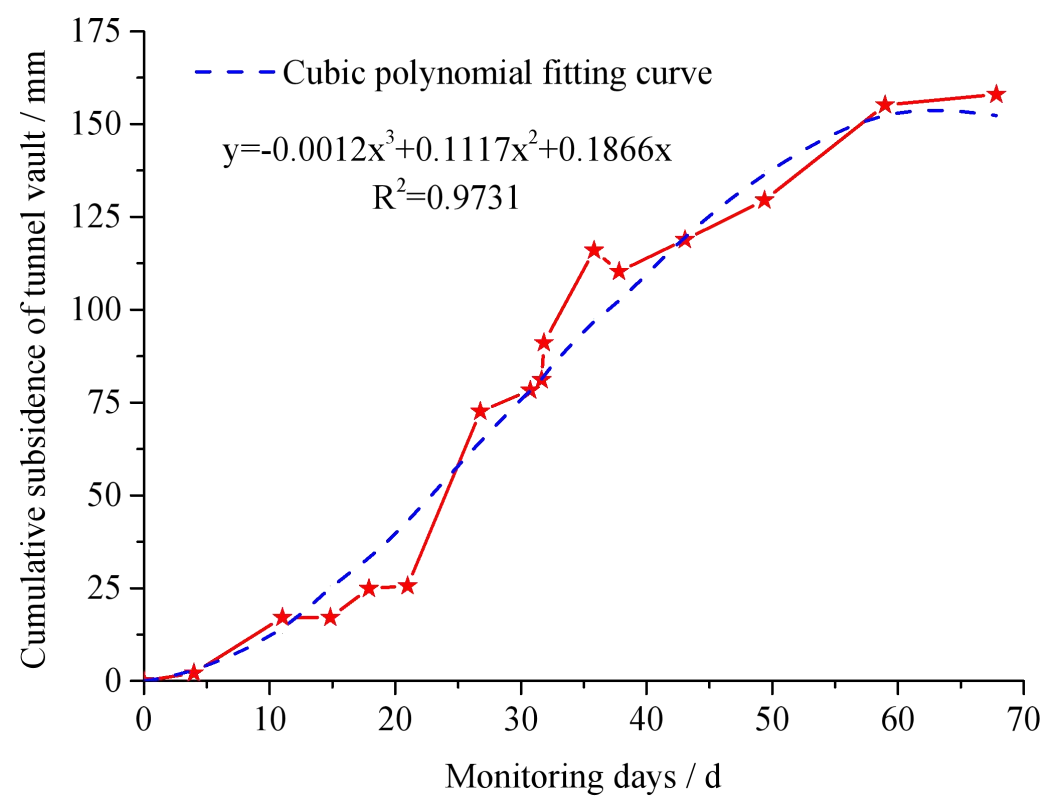

Fig. 4 Statistical analysis of cumulative subsidence measured at different points

The further to analyse the position of the inflection point on the deformation profile, a cubic polynomial is used to fit the measured data such that:

$$
Y=-0.0012 x^{3}+0.1117 x^{2}+0.1866 x
$$

The correlation coefficient is: $\mathrm{R}=98.6 \%$.

Let the second derivative of $Y(x)$ be 0 , it can be calculated that the inflection point is at $X_{\text {拐 }} \approx 31 d$, that is, the rate of deformation is found to change from increasing to decreasing on the $31^{\text {st }}$ day.

\section{Loosening of rock in the fault fracture zone under excavation disturbance during tunnelling}

\subsection{Stress redistribution in surrounding rocks caused by tunnel excavation}

As the tunnel passes through the fault fracture zone, the surrounding rocks in the fault fracture zone of the tunnel tend to change from an elastic state to a plastic state and form a plastic broken rock zone; with increasing distance from the cavern wall, the radial stress $\sigma_{\mathrm{rp}}$ 
in the rock surrounding the cavern grows from zero and the stress state in the surrounding rock changes from an axial to a biaxial state. As a result, the plastic zone in the surrounding rocks is transformed to an elastic zone. Due to occurrence of the plastic broken-rock zone, the stress within a certain range of the zone decreases because of the concomitant stress relief therein. In addition, the locus of maximum stress concentration shifts from the cavern wall to the boundary of the plastic and elastic zones, increasing the stress in the elastic zone.

As shown in Fig 5, suppose that a circular tunnel with the radius of $R_{0}$ is excavated in a homogeneous, continuous, isotropic rock, and the radius of the plastic broken rock zone formed after excavation is $R_{p}$. Then, the circular cavern is in an isotropic $\left(\sigma_{0}=\gamma Z\right)$ hydrostatic stress field and the strength of the surrounding rocks conforms to the Mohr-Coulomb linear strength criterion. A unit in the plastic zone at distance $r$ from the centre of the tunnel is selected. When not considering the body force of the unit itself, it satisfies the symmetric condition and the shear stress on the elemental area is 0 . Under these conditions, the stress is only related to the variable $r$ while remaining independent of $\theta$, therefore, the radial stress $\sigma_{r p}$ and the tangential stress $\sigma_{\theta \mathrm{p}}$ are both principal stresses (major and minor, respectively).

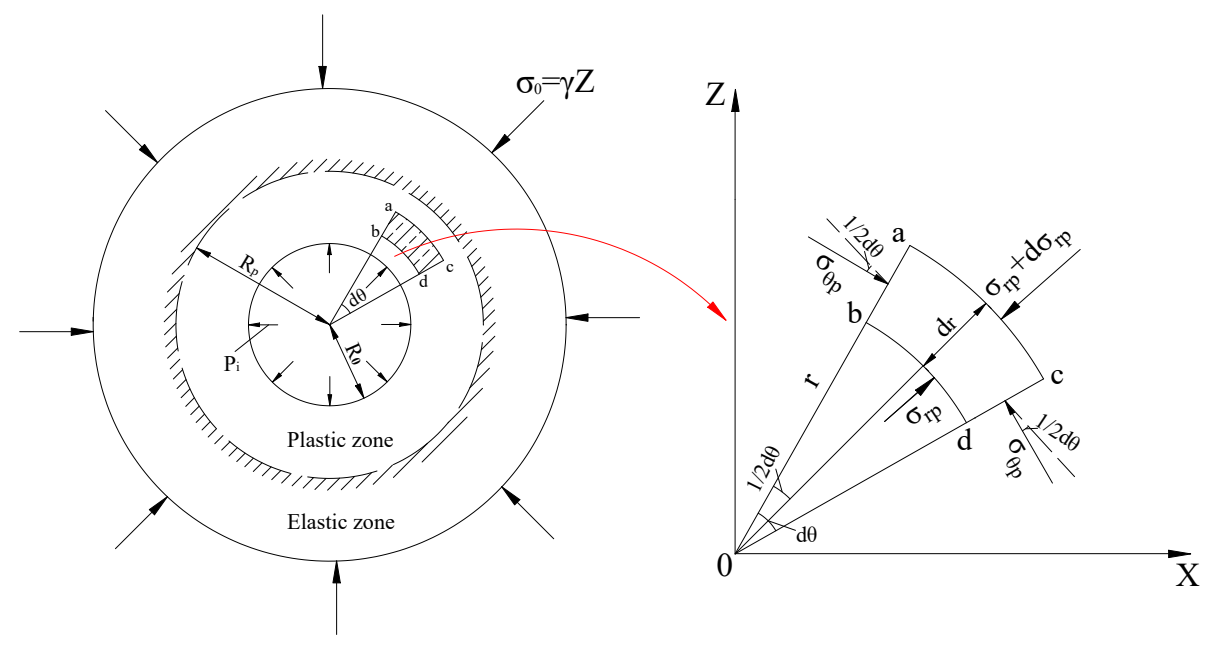

Fig. 5 Analysis of the stress in the rock surrounding the plastic zone Let $\sum \sigma_{r p}=0$, the equilibrium equation along the $r$ direction is obtained as follows:

$$
\left(\sigma_{r p}+\frac{\partial \sigma_{r p}}{\partial r} d r\right)(r+d r) d \theta-\sigma_{r p} r d \theta-2 \sigma_{\theta p} d r \sin \frac{d \theta}{2}=0
$$

If $d \theta$ is very low, then $\sin \frac{d \theta}{2} \cong \frac{d \theta}{2}$, the following can be obtained after expanding the 
above equation and ignoring the high-order small quantity:

$$
\frac{\partial \sigma_{r p}}{\partial r}+\frac{\sigma_{r p}-\sigma_{\theta p}}{r}=0
$$

For weak and broken rocks, their shear failure can be evaluated using Mohr-Coulomb strength theory:

$$
\sin \varphi=\frac{\sigma_{\theta p}-\sigma_{r p}}{\sigma_{\theta p}+\sigma_{r p}+2 \cot \varphi}
$$

Simultaneous equations are then constructed: when using the boundary condition $r=R_{0}$, then $\sigma_{r p}=p_{i}$, where $p_{i}$ represents the support resistance.

The radial stress is given by $\sigma_{r \rho}=\left(p_{i}+c \cot \varphi\right)\left(\frac{r}{R_{0}}\right)^{\frac{2 \sin \varphi}{1-\sin \varphi}}-c \cdot \cot \varphi$

The tangential stress is given by $\sigma_{\theta \rho}=\frac{1+\sin \varphi}{1-\sin \varphi}\left(p_{i}+c \cot \varphi\right)\left(\frac{r}{R_{0}}\right)^{\frac{2 \sin \varphi}{1-\sin \varphi}}-c \cdot \cot \varphi$

It can be seen from this that the redistributed stress in surrounding rocks in the plastic zone is independent of the natural stress on the rock. Instead, it is dependent on the support resistance $p_{i}$ and the indicators of shear strength of rocks ( $\mathrm{c}$ and $\varphi$ ).

According to the theory of elasticity, when the lateral pressure coefficient of rocks is $\lambda=1$, the stress in rock mass in the elastic zone after tunnel excavation meets the following conditions:

$$
\left\{\begin{array}{l}
\sigma_{r \mathrm{e}}=\sigma_{0}\left(1-\frac{R_{0}^{2}}{r^{2}}\right)+\mathrm{p}_{i} \frac{R_{0}^{2}}{r^{2}} \\
\sigma_{\theta \mathrm{e}}=\sigma_{0}\left(1+\frac{R_{0}^{2}}{r^{2}}\right)-\mathrm{p}_{i} \frac{R_{0}^{2}}{r^{2}} \\
\tau_{r \theta e}=0
\end{array}\right.
$$

On the boundary between the elastic and plastic zones, $\sigma_{\theta \mathrm{p}}$ and $\sigma_{r p}$ can be calculated either using the stress formula for the elastic zone or that for the plastic zone, giving $\sigma_{r e}=\sigma_{r p}$, $\sigma_{\theta e}=\sigma_{\theta p}, \quad \sigma_{r e}+\sigma_{\theta e}=\sigma_{r p}+\sigma_{\theta p}$

By substituting the stress predicted by formula applicable to the elastic and plastic zones into the above formula, it can be obtained that.

$$
\sigma_{r e}+\sigma_{\theta e}=2 \sigma_{0}
$$




$$
\sigma_{r p}+\sigma_{\theta p}=\frac{2}{1-\sin \varphi}\left(\mathrm{p}_{\mathrm{i}}+c \cot \varphi\right)\left(\frac{r}{R_{0}}\right)^{\frac{2 \sin \varphi}{1-\sin \varphi}}-2 c \cdot \cot \varphi
$$

Then $2 \sigma_{0}=\frac{2}{1-\sin \varphi}\left(\mathrm{p}_{i}+c \cot \varphi\right)\left(\frac{R_{\mathrm{p}}}{R_{0}}\right)^{\frac{2 \sin \varphi}{1-\sin \varphi}}-2 c \cdot \cot \varphi$

Therefore, the radius of the plastic zone is given by

$$
R_{p}=R_{0}\left[\frac{\sigma_{0}(1-\sin \varphi)-c \cdot \cos \varphi+c \cdot \cot \varphi}{p_{i}+c \cot \varphi}\right]^{\left(\frac{1-\sin \varphi}{2 \sin \varphi}\right)}
$$

212

\subsection{Distribution characteristics of deformation of surrounding rocks during tunnel}

\section{excavation}

Previous research on the distribution of displacement induced by blasting excavation of tunnels focuses more on the magnitude of displacement on the transverse section of the tunnel. As shown in Fig 6, ignoring the dilation of the surrounding rocks, the displacement $u^{*}$ at the boundary of the plastic zone and the displacement $u$ of the tunnel wall can be expressed by Formula (9) and (10), where, according to Formula (8):

$$
u^{*}=\frac{1+\mu}{E} R_{p}\left(\sigma_{0} \sin \varphi+c \cdot \cos \varphi\right)
$$

$$
u=\frac{R_{p}}{R_{0}} u^{*}+\frac{K\left(R_{p}^{2}-R_{0}^{2}\right)}{2 R_{0}}
$$

where $R_{0}$ and $R_{p}$ separately refer to the radii of the tunnel and the plastic zone; $\sigma_{0}, P_{i}, \varphi$, $\mu, E$, and $K$ denote the initial geostress, support resistance, internal friction angle, Poisson's ratio, elastic modulus, and bulk modulus, respectively.

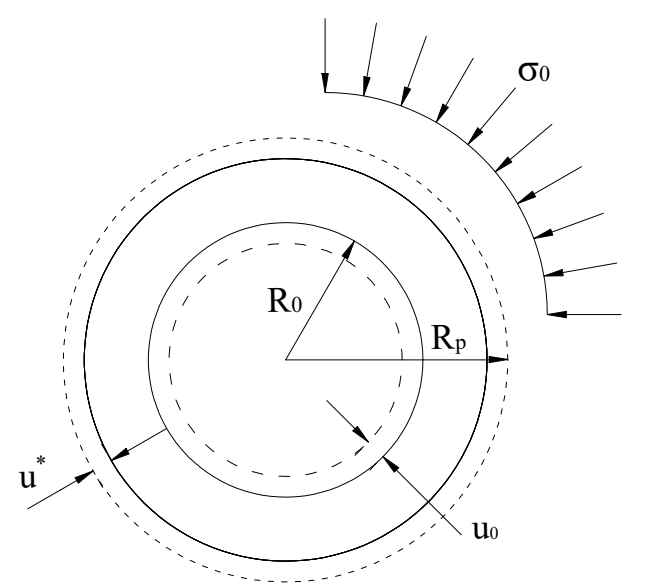

Fig. 6 Radial displacement of surrounding rocks 
The displacement of the tunnel wall is approximately directly proportional to the square of the radius of the plastic zone, and the surrounding rocks are significantly deformed under conditions of a low internal friction angle or high geostress. During the normal excavation of the tunnel, when encountering the fracture zone, that is, when the quality of the surrounding rock changes significantly on the longitudinal section, the displacement shows an abrupt increase.

The research into deformation profiles on the longitudinal section is mainly limited by the three-dimensional (3-d) nature of the problem. Previous research on convergence and deformation of formations due to tunnel excavation also mainly takes the radial displacement of the tunnel as the research object ${ }^{[32]}$. Under the assumption of linear elasticity, the radial deformation of rock surrounding a circular tunnel can be expressed in polar coordinates:

$$
U_{r}=\eta \frac{\sigma_{l} R^{2}(1+\mu)}{2 E r}\left\{1+\lambda+(1-\lambda)\left[4(1-\mu)-\frac{R^{2}}{r}\right] \cos (2 \theta)\right\}
$$

where $\lambda, \mu, \sigma_{1}$, and $\eta$ separately represent the lateral pressure coefficient, Poisson's ratio, maximum overburden pressure, and constraint loss.

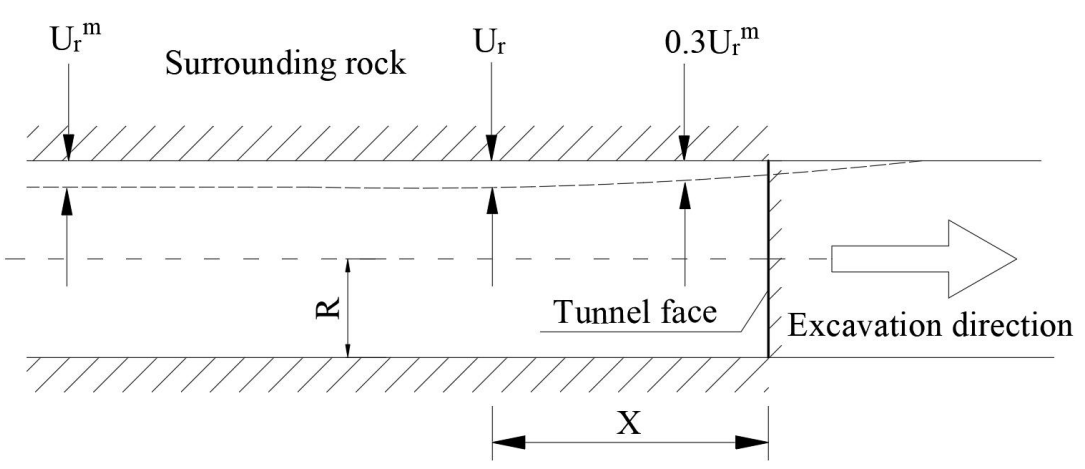

Fig. 7 Numerical model of the profile of radial displacement along the tunnel axis

After considering the elastic and plastic deformation of rocks, empirical formulae were used to describe the ratio of the radial deformation to the maximum deformation of the surrounding rock at different distances from the tunnel face. It is supposed that the far-field stress on the rocks is homogeneous, so the profile of radial displacement along the tunnel axis can be calculated using the numerical model for the problem shown in the Fig.7, and the profile represents the longitudinal section of the unlined tunnel with a radius of $R$ near the tunnel face. The radial displacement is $U_{r}$ at distance $X$ from the tunnel face. If $X$ is large, the radial displacement reaches its maximum. For negative values of $X$ (i.e., for positions ahead of the tunnel face), the 
radial displacement decreases, and the displacement at a shorter distance ahead of the tunnel face is practically 0 , for example,

$$
\text { Panet }{ }^{[33]} \text { proposed that }
$$

$$
\frac{U_{r}}{U_{\max }}=\alpha_{0}+\left(1-\alpha_{0}\right)\left[1-\left(\frac{m}{m+Z / R}\right)^{2}\right]
$$

Hoek ${ }^{[34]}$ and Carranza-Torres ${ }^{[35]}$ point outed that

$$
\frac{U_{r}}{U_{\max }}=\left[1+\exp \left(\frac{-Z}{1.1 R}\right)\right]^{-1.7}
$$

Most empirical formulae used to describe the deformation at longitudinal sections are summarised based on numerous items of in-situ monitoring data pertaining to deformation and can intuitively reflect the changes in radial displacement of the unsupported tunnel wall. Whereas, after considering the influence of the fault fracture zone ahead of the tunnel face, the deformation distribution on the longitudinal section of the tunnel becomes more complicated. In the case, it needs to be analysed from the $3-\mathrm{d}$ perspective using numerical calculation ${ }^{[36-38]}$.

\section{Numerical simulation and verification of the excavation process}

The rock samples collected from the fracture zone in the field were analysed by conducting the laboratory test ${ }^{[39]}$. Besides, the HJC constitutive model was used for numerical calculation. The material parameters of the model are shown in Table 2. Based on the field test, the tested data of effective geostress were obtained at depths of 15.0, 18.5, 22.0, and $27.0 \mathrm{~m}$ in the main auxiliary tunnel of the inclined shaft (Table 3).

Table 2 Material parameters of the HJC numerical model

\begin{tabular}{ccccccccccccccccccccccc}
\hline Type & $\rho /$ & $\mathrm{G} /$ & $\mathrm{A}$ & $\mathrm{B}$ & $\mathrm{C}$ & $\mathrm{N}$ & $f_{\mathrm{c}}$ & $\mathrm{T} /$ & $\mathrm{D}$ & $\mathrm{P} \mathrm{c}_{\mathrm{c}}$ & $\mu_{\mathrm{c}}$ & $\mathrm{P}_{l}$ & $\mu_{l}$ & $\mathrm{k}_{1}$ & $\mathrm{k}_{2}$ & $\mathrm{k}_{3}$ \\
& $\mathrm{~kg} / \mathrm{m}^{3}$ & $\mathrm{GPa}$ & & & & & $\mathrm{MPa}$ & $\mathrm{MPa}$ & & $\mathrm{MPa}$ & & $\mathrm{GPa}$ & $\mathrm{GPa}$ & $\mathrm{GPa}$ & $\mathrm{GPa}$ \\
\hline Surrounding rock & 2620 & 15.2 & 0.88 & 1.9 & 0.009 & 0.77 & 56 & 4.54 & 0.05 & 17.3 & 0.001 & 0.88 & 0.1 & 90 & -197 & 228 \\
Fracture zone & 1890 & 9.9 & 0.53 & 1.2 & 0.004 & 0.42 & 33 & 2.86 & 0.024 & 13 & 0.001 & 0.78 & 0.1 & 63 & -142 & 169 \\
\hline
\end{tabular}

Notes: $\rho, G, A, B, C, N, f_{\mathrm{c}}, T$, and $D$ represent the density, shear modulus, normalised cohesive strength, normalised pressure hardening coefficient, strain-rate hardening exponent, pressure hardening exponent, quasi-static compressive strength, maximum tensile stress of materials, and damage parameter, respectively; $P_{\mathrm{c}}, \mu_{\mathrm{c}}, P_{l}$, and $\mu_{l}$ denote the hydrostatic pressure, volumetric strain, hydrostatic pressure under compaction, and volumetric strain corresponding to the hydrostatic pressure under compaction; $k_{1}, k_{2}$, and $k_{3}$ are pressure constants. 
Table 3 The hydrofracturing results from vertical boreholes

\begin{tabular}{cccccc}
\hline & \multicolumn{7}{c}{ Measuring depth of position / m } & Geostress of Calculation Model \\
\hline Geostress direction & 15 & 18.5 & 22 & 27 & \\
\hline $\begin{array}{c}\text { Maximum horizontal } \\
\text { principal stress / MPa }\end{array}$ & 23.55 & 25.14 & 23.04 & 24.81 & 24 \\
$\begin{array}{c}\text { Minimum horizontal } \\
\text { principal stress / MPa }\end{array}$ & 12.95 & 13.45 & 13.77 & 13.37 & 13.4 \\
$\begin{array}{c}\text { Perpendicular stress / MPa } \\
\text { Mend }\end{array}$ & 12 & 12.09 & 12.18 & 12.3 & 12 \\
\hline
\end{tabular}

Based on the above test results, the physico-mechanical parameters and geostress of the rock mass were input to the calculation model. By using the ANSYS/LS-DYNA numerical simulation software, a 3-d calculation model for the excavation of the deep tunnel crossing the fault zone was built. For the convenience of obtaining deformation characteristics of surrounding rocks of the tunnel, a one-half scale model was used for calculation. The model measures $200 \mathrm{~m} \times 50 \mathrm{~m} \times 100$ m (length $\times$ width $\times$ height), as shown in Fig. 8. It is supposed that the excavated length of the tunnel model is $120 \mathrm{~m}$, the cross-section of the tunnel is that of a circular arch, and the tunnel excavation has a span of $15.0 \mathrm{~m}$ and height of $13.0 \mathrm{~m}$. The width of the fault fracture zone is $10 \mathrm{~m}$ according to that of the collapse zone. For convenience of subsequent calculation and analysis, the dip angle of the fault fracture zone is set to $90^{\circ}$.

285
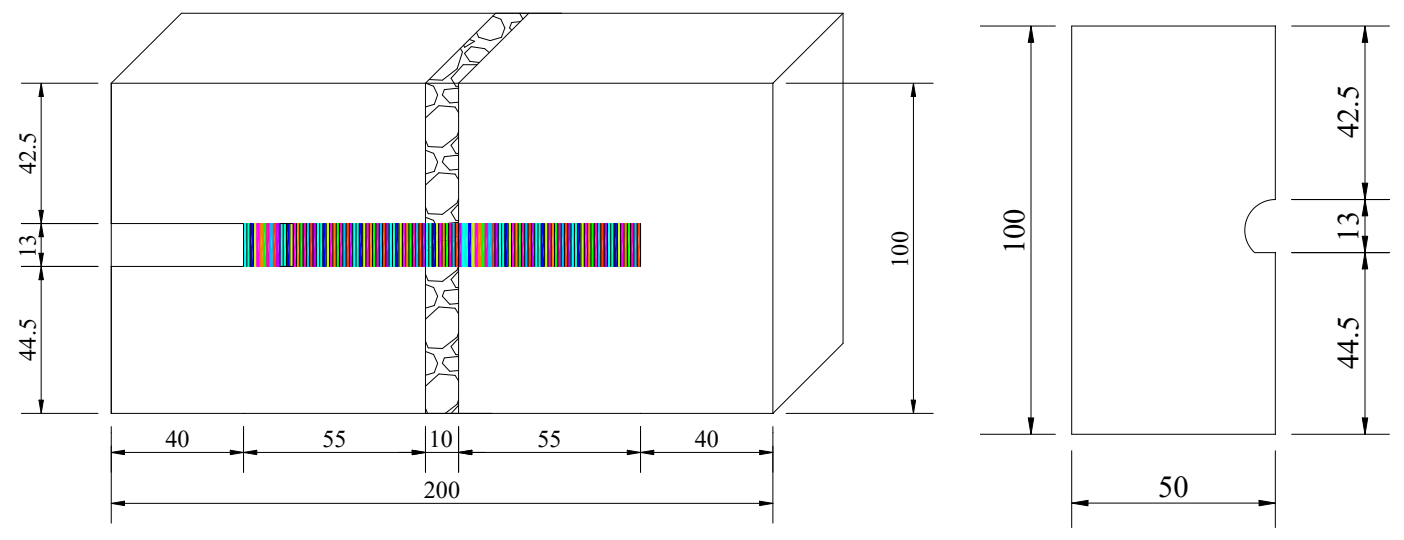

Fig. 8 Dimensions of the numerical model (unit: m)

The numerical model is built using eight-node hexahedron elements, including 187,880 elements and 200,850 nodes (Fig. 9). Full-face excavation is performed from left to right at the rate of $1 \mathrm{~m} / \mathrm{d}$ by referring to the practical excavation process. 


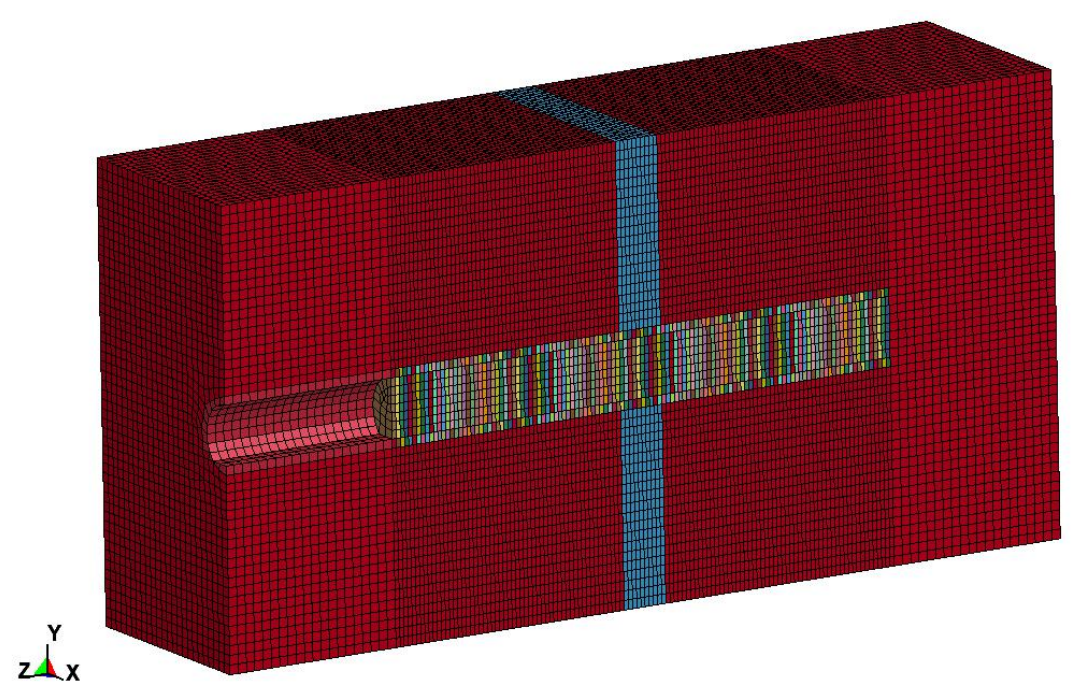

Fig. 9 Finite-element mechanical model

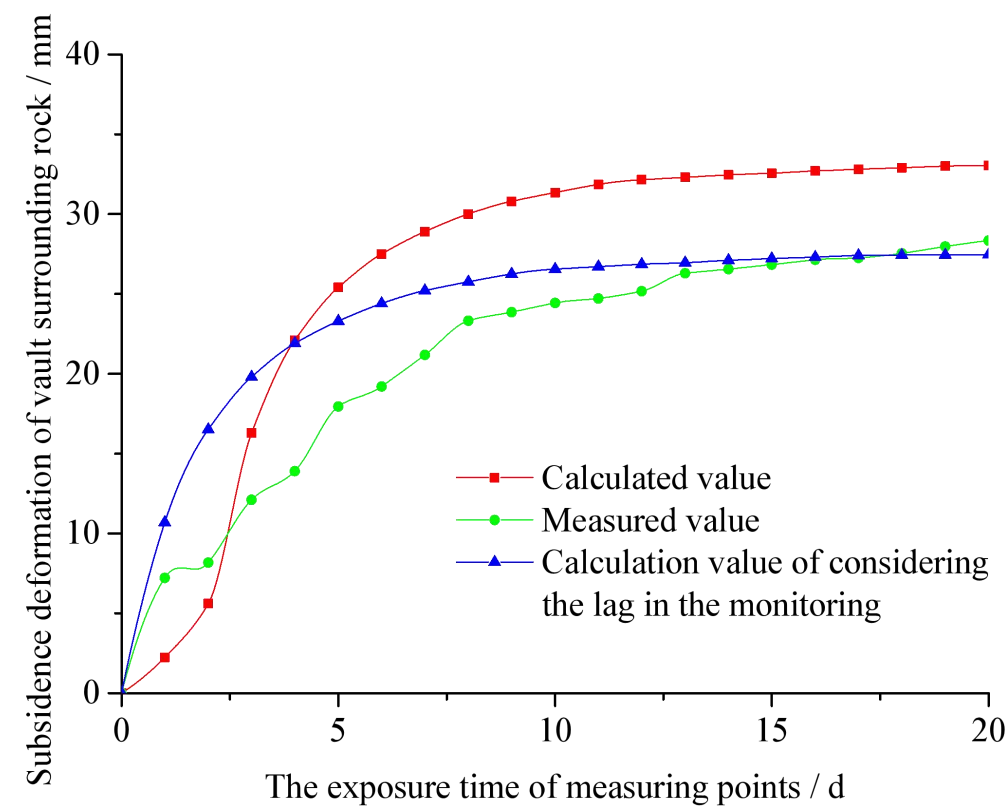

Fig. 10 Data measured in the tunnel and numerically calculated deformation profiles for surrounding rocks

Comparison of the calculated and measured subsidence at monitoring points in the vault $38 \mathrm{~m}$ from the fracture zone (Fig. 10) shows that there is certain deviation between the calculated and measured results. On the one hand, an obvious increase in the deformation rate is observed on the calculated deformation profile one day after excavation at the monitoring point, that is, there is an apparent inflection point for the deformation; however, no such inflection point is observed on the measured profile. Considering that it is a high-risk task to measure deformation in the close vicinity of the tunnel face immediately after excavation of the monitoring point in engineering 
practice, the actual monitoring is generally carried out one, or even several days after excavation [40]. Therefore, considering the lag of the practical monitoring, the deformation profile obtained through calculation is translated leftward, to obtain a new curve. Comparison shows that the calculated and measured deformation curves considering the lag in the monitoring match in terms of the trend in deformation or specific values thereof.

5 Deformation characteristics of rock surrounding the fault fracture zone under full-face excavation

\subsection{Numerical simulation to predict likely fracture zones using the deformation profile of} the rock surrounding the tunnel The tunnel was excavated at a footage of $1 \mathrm{~m} / \mathrm{d}$ from the position where the tunnel face was $55 \mathrm{~m}$ from the fracture zone, until the fracture zone was just exposed (Fig. 11). Before tunnelling through the fracture zone, deformation curves at elements in the vault 50, 45, 40, 35, 30, 25, 20, $15,10,5$, and $1 \mathrm{~m}$ from the fracture zone with the day of excavation were obtained. On this basis, the relationship between deformation of the surrounding rock and the fracture zone ahead was ascertained.

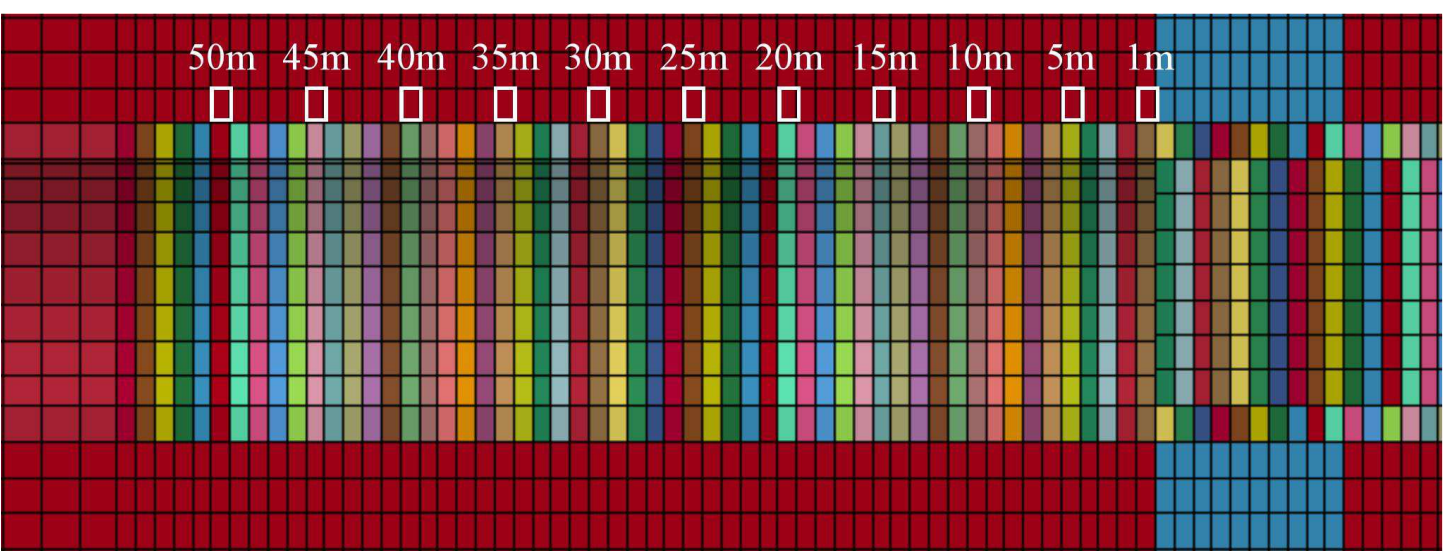

Fig. 11 Layout of monitoring points in the rock surrounding the tunnel

The excavation is stopped when the tunnel face reaches the position where the fracture zone is exposed. In this way, cumulative deformation in $70 \mathrm{~d}$ at various monitoring points is obtained (Fig. 12). It is found that subsidence and deformation of surrounding rocks differ with distance from the tunnel face as it advances towards the fracture zone. In the tunnel section far from the fracture zone, the change rate of deformation of surrounding rocks first increases, then gradually decreases with further excavation; when the tunnel face is less than $20 \mathrm{~m}$ from the fracture zone, the rocks in the region around the fracture zone were deformed substantially, and the total 
cumulative deformation energy is larger. Therefore, within a certain range, the closer the monitoring points are to the fracture zone, the larger the deformation recorded before excavation thereat. According to the stress analysis, this happens because of the low rigidity of the fracture zone, so surrounding rocks closer to the fracture zone are weakly confined, which allows their greater deformation in the early stages of the excavation.

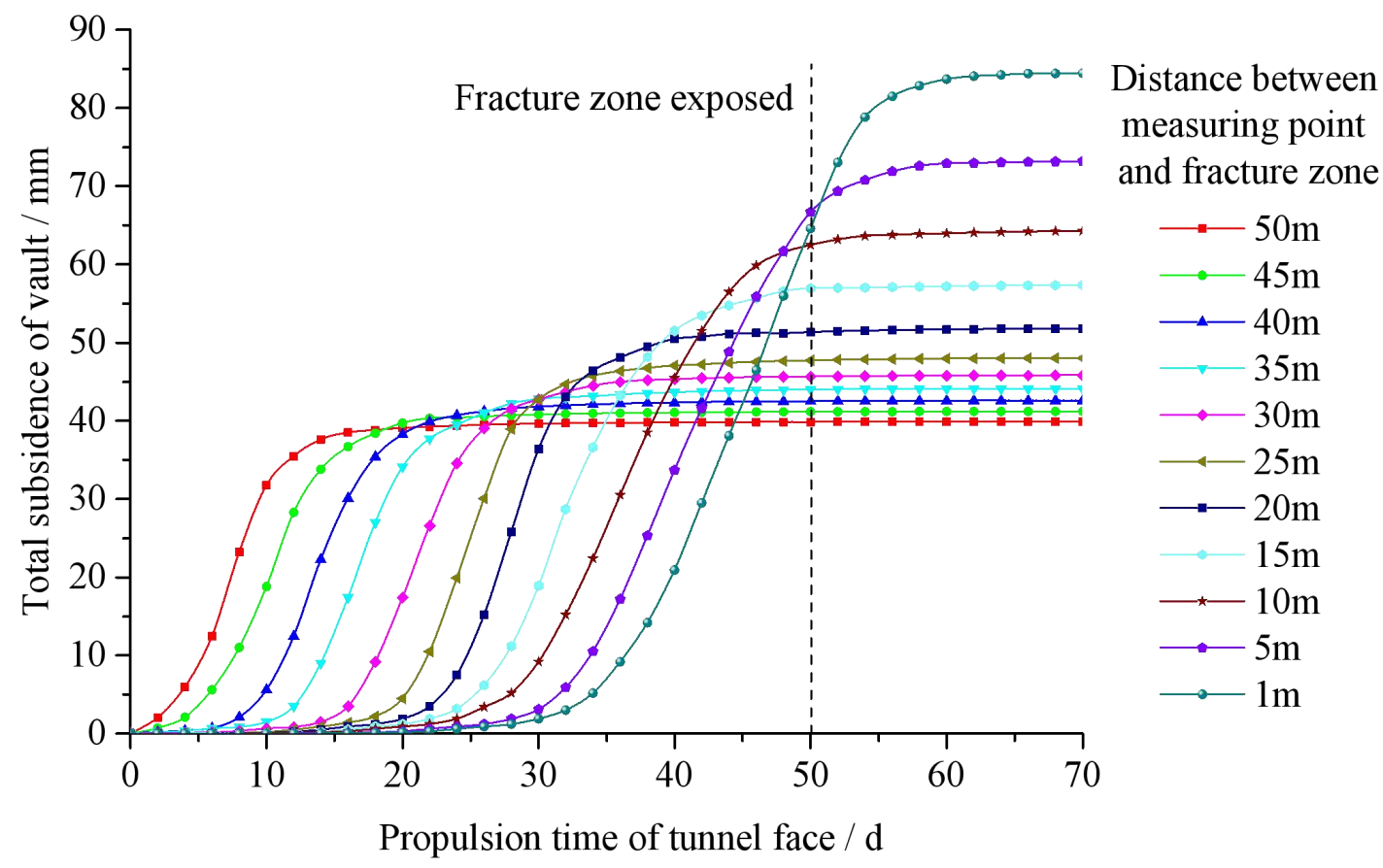

Fig. 12 Calculated cumulative subsidence at different positions

Considering the ideal monitoring in the practice, that is, the deformation monitoring starts at the same time as the excavation reaches the monitoring point, then the calculated cumulative subsidence after exposure of monitoring points at different points is as shown in Fig. 13: the monitoring point $50 \mathrm{~m}$ from the fracture zone shows the maximum cumulative subsidence at $20 \mathrm{~d}$ after its exposure, while the monitoring point at $20 \mathrm{~m}$ from the fracture zone shows the minimum subsidence. By analysing the deformation profiles of different monitoring points after exposure, it is evident that an inflection point is present on the curves at some monitoring points far from the fracture zone. The inflection point functions as an indicator of the presence of a fracture zone ahead of the tunnel. This indicates that the numerical model can be used to simulate and analyse the deformation of exposed rock surrounding such a tunnel in engineering practice. 


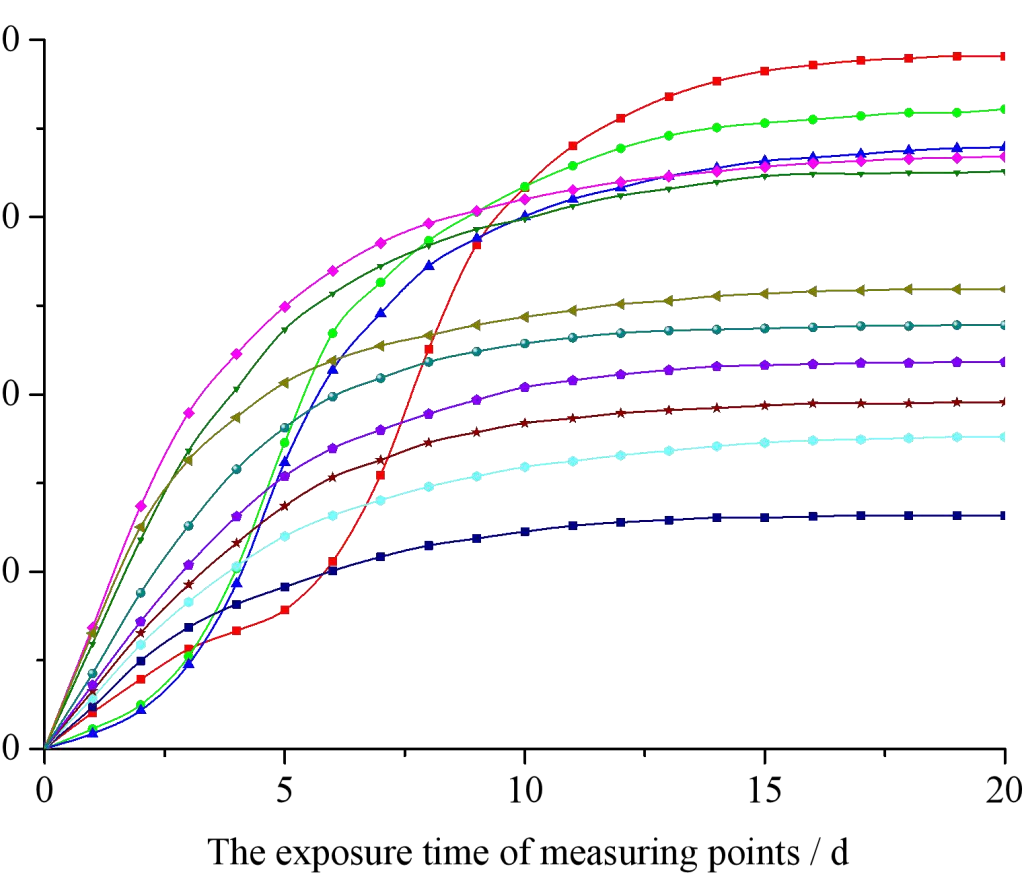

Distance between measuring point and fracture zone

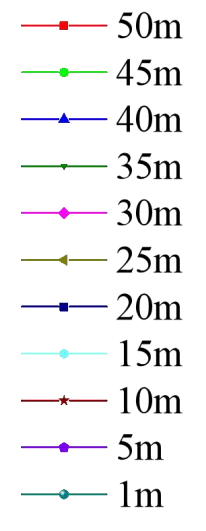

Fig. 13 Calculated cumulative subsidence after exposure of monitoring

points at different positions

\subsection{Deformation of surrounding rocks under different forms of advanced support}
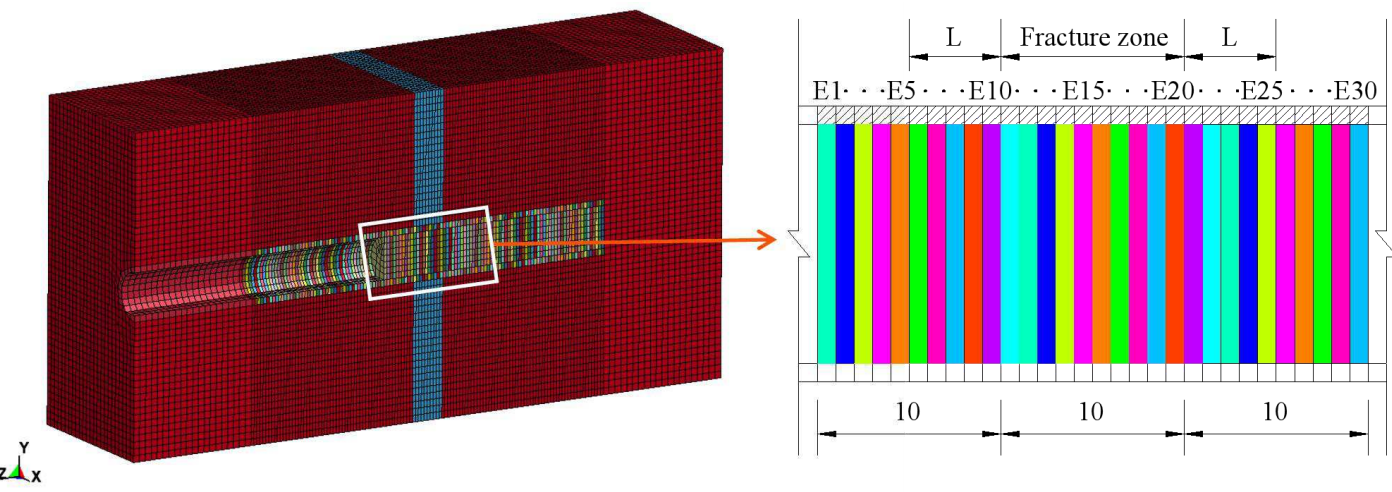

Fig. 14 Surrounding rocks in, and around, the fracture zone before excavation

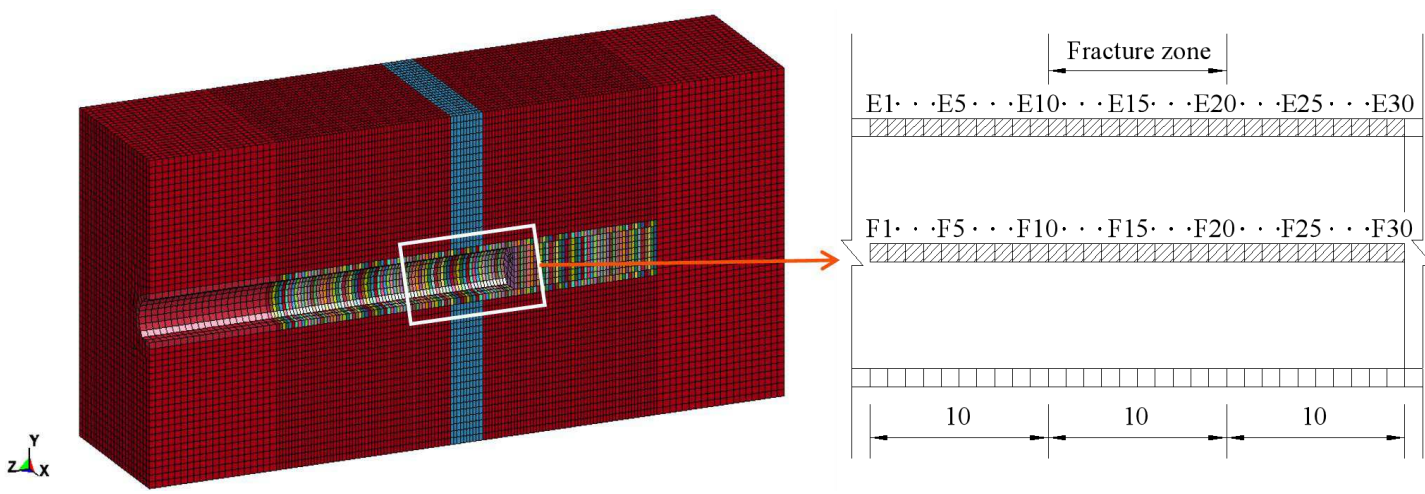

Fig. 15 Surrounding rocks in, and around, the fracture zone after excavation 
The tunnel was excavated from a position $10 \mathrm{~m}$ ahead of the fracture zone to one $10 \mathrm{~m}$

behind it. Elements in the fracture zone and within $10 \mathrm{~m}$ ahead and behind the fracture zone were selected to analyse the displacement. The model before and after excavation and the selected analysis elements are shown in Figs 14 and 15. The analysis was conducted on elements with an interval of $1 \mathrm{~m}$. The elements of monitoring points in the vault of the tunnel were labelled as E1 to E30, while those in the sidewalls were labelled F1 to F30. On this basis, the influences of different material properties and lengths of advanced support on the subsidence and convergence of surrounding rock in, and around, the fracture zone were investigated.

\subsubsection{Different materials of advanced support}

To analyse the influences of different materials used in the advanced support system on the deformation of the rock surrounding the fracture zone after tunnel excavation, the length of the advanced support is set to $12 \mathrm{~m}$, and $L$ is set to $1 \mathrm{~m}$ beyond the fracture zone at each end. The HJC constitutive model is also used for the support materials. Table 4 lists the main mechanical parameters of the six groups of support materials. Figs 16 and 17 compare the deformation (subsidence and convergence) curves of surrounding rocks in, and around, the fracture zone when using different support-material parameters.

Table 4 Material parameter used to model the advanced support in the HJC model

\begin{tabular}{|c|c|c|c|c|c|c|c|c|c|c|c|c|c|c|c|c|}
\hline No. & $\rho /$ & $\mathrm{G} /$ & A & B & $\mathrm{C}$ & $\mathrm{N}$ & $f_{\mathrm{c}}$ & $\mathrm{T} /$ & $\mathrm{D}_{1}$ & $\mathrm{P}_{\mathrm{c}}$ & $\mu_{\mathrm{c}}$ & $\mathrm{P}_{l}$ & $\mu_{l}$ & $\mathrm{k}_{1}$ & $\mathrm{k}_{2}$ & $\mathrm{k}_{3}$ \\
\hline & $\mathrm{kg} / \mathrm{m}^{3}$ & GPa & & & & & $\mathrm{MPa}$ & $\mathrm{MPa}$ & & $\mathrm{MPa}$ & & $\mathrm{GPa}$ & & $\mathrm{GPa}$ & $\mathrm{GPa}$ & $\mathrm{GPa}$ \\
\hline 1 & 2700 & 15.6 & 0.93 & 2.0 & 0.009 & 0.80 & 62 & 4.87 & 0.053 & 18 & 0.001 & 0.91 & 0.1 & 96 & -208 & 240 \\
\hline 2 & 2800 & 15.8 & 0.98 & 2.13 & 0.0097 & 0.86 & 66.7 & 5.16 & 0.057 & 18.67 & 0.001 & 0.94 & 0.1 & 99.67 & -220 & 251 \\
\hline 3 & 2900 & 16.1 & 1.02 & 2.27 & 0.0103 & 0.93 & 71.3 & 5.45 & 0.062 & 19.33 & 0.001 & 0.98 & 0.1 & 103.33 & -233 & 261 \\
\hline 4 & 3000 & 16.3 & 1.07 & 2.40 & 0.0110 & 0.99 & 76.0 & 5.74 & 0.066 & 20.00 & 0.001 & 1.01 & 0.1 & 107.00 & -245 & 272 \\
\hline 5 & 3100 & 16.6 & 1.12 & 2.53 & 0.0117 & 1.05 & 80.7 & 6.03 & 0.070 & 20.67 & 0.001 & 1.04 & 0.1 & 110.67 & -257 & 283 \\
\hline 6 & 3200 & 16.8 & 1.16 & 2.67 & 0.0123 & 1.12 & 85.3 & 6.32 & 0.075 & 21.33 & 0.001 & 1.08 & 0.1 & 114.33 & -270 & 293 \\
\hline
\end{tabular}

As shown, the surrounding rocks around the fracture zone exhibit slight differences in deformation; while those in the fracture zone show significantly different deformations, with the maximum subsidence reducing from 107.8 to $64.5 \mathrm{~mm}$ and maximum convergence decreasing from 78.2 to $48.4 \mathrm{~mm}$. When increasing the strength of material used in the advanced support, deformation in the surrounding rock decreased significantly. In particular, the subsidence and convergence of surrounding rocks show large changes when using materials 1 to 4 in the advanced 

support on deformation of surrounding rocks of the tunnel gradually weakens and the support becomes harder to build and install.

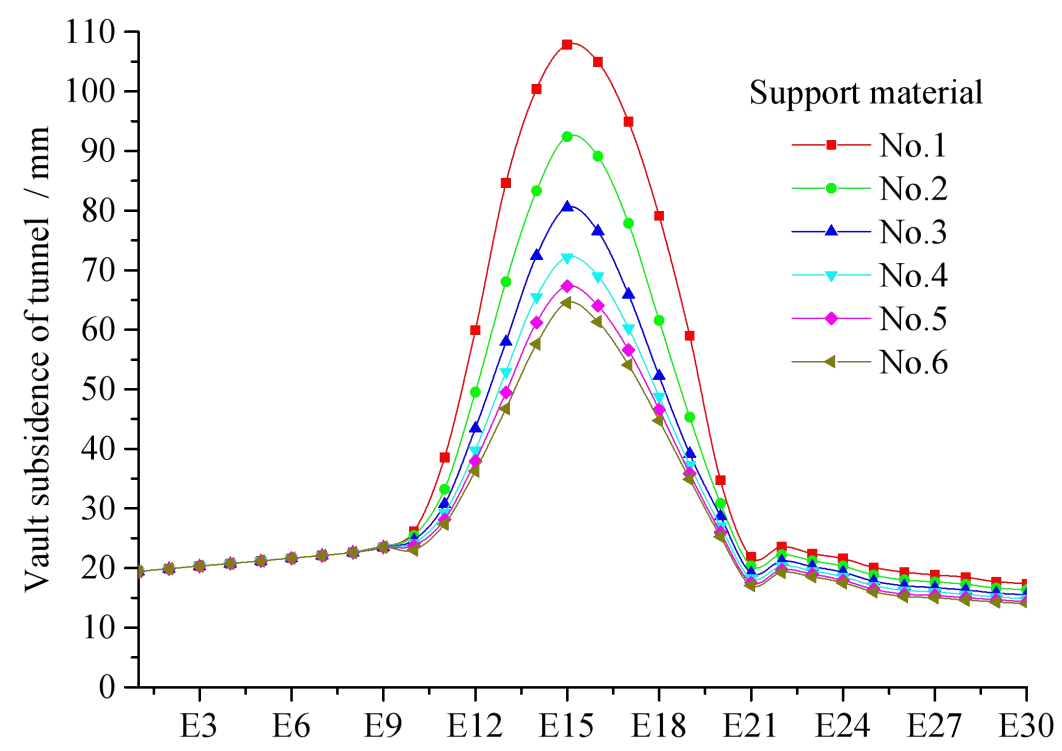

Units of measuring points for exposed surrounding rock

Fig. 16 Calculated subsidence of surrounding rocks in the vault under advanced

support with materials of different properties

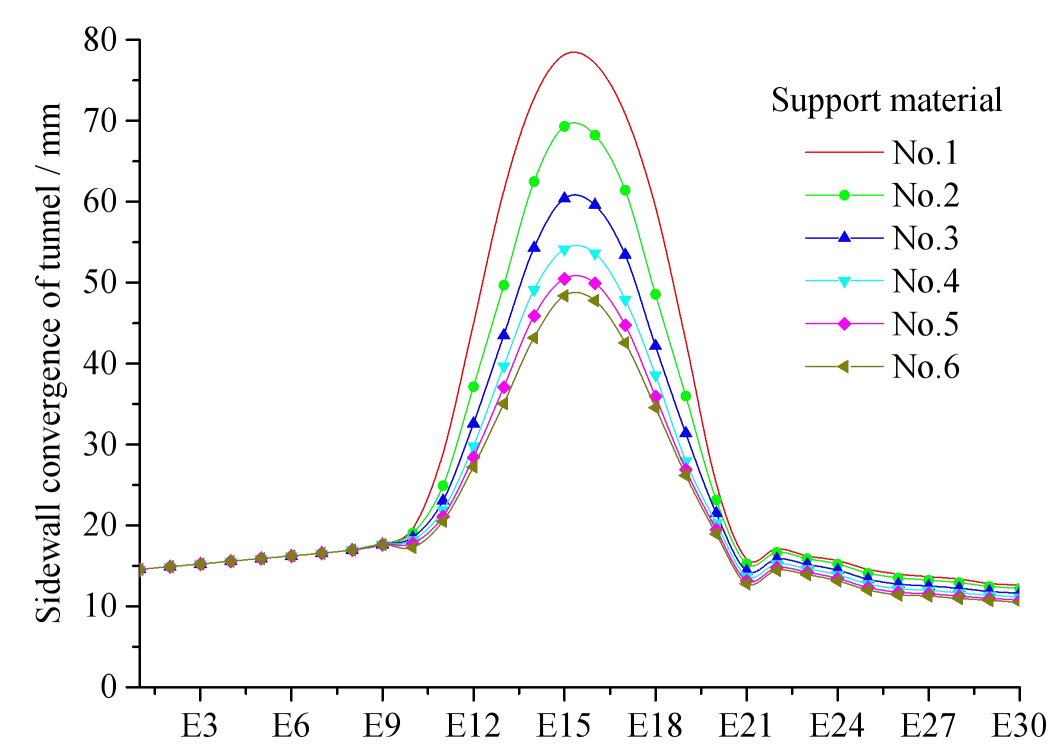

Units of measuring points for exposed surrounding rock

Fig. 17 Calculated convergence of surrounding rocks under advanced support with materials of different properties

At the same time, it is found that the deformation of surrounding rocks remained relatively large, which indicates that the advanced support implemented only in the section of the fracture 

Therefore, the following section further discusses the control effect of the length of advanced support on deformation of surrounding rocks in, and around, the fracture zone.

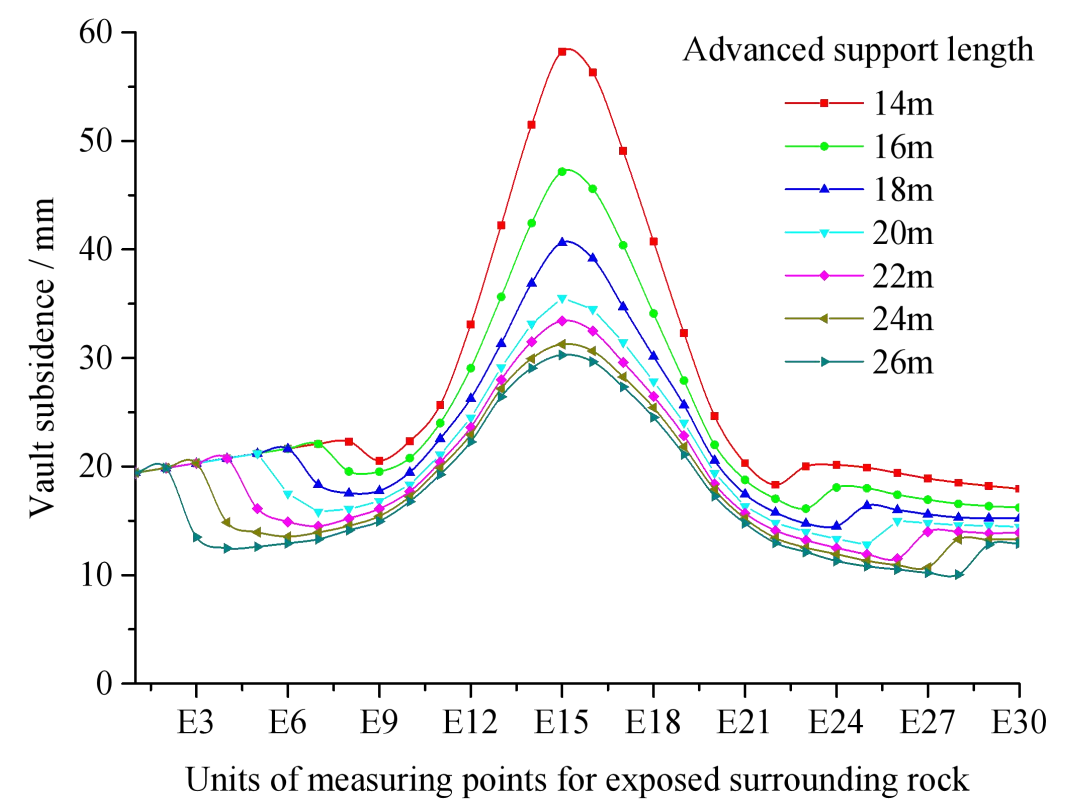

Fig. 18 Calculated subsidence of surrounding rocks in the vault under different lengths of advanced support

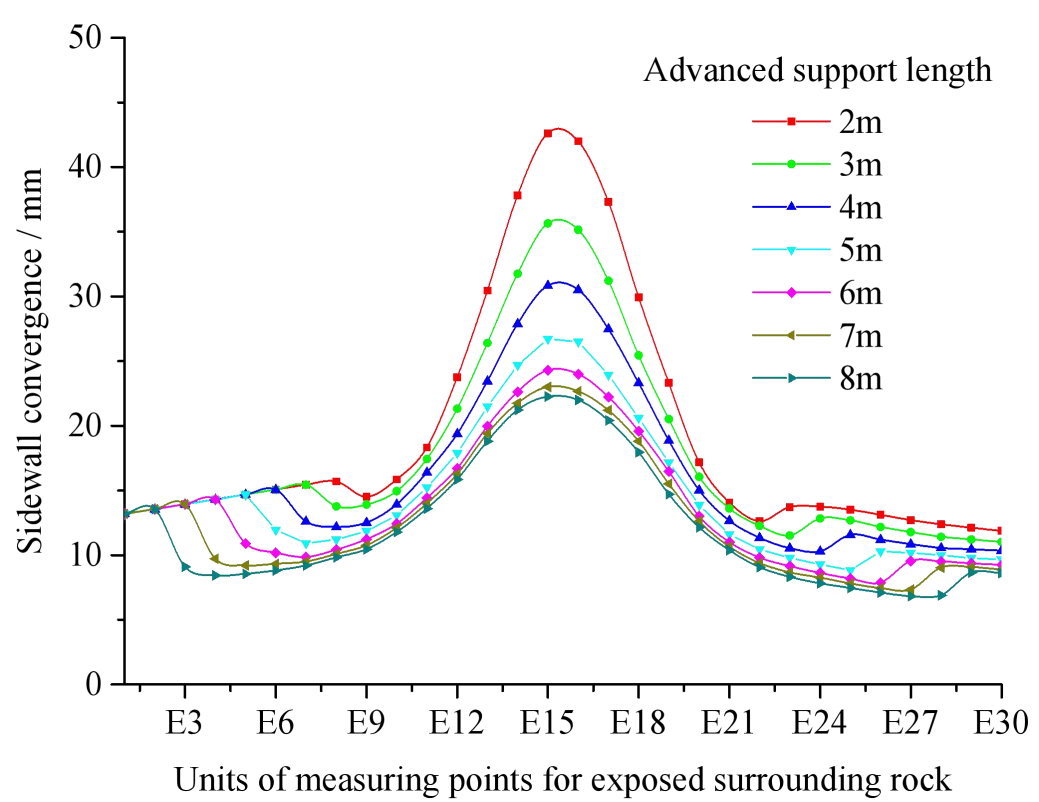

Fig. 19 Calculated convergence of surrounding rocks in the sidewalls under different lengths of advanced support 
benchmark, the influences of the length of advanced support on the deformation of the fracture zone were further analysed. Here, the lengths of the advanced support for the fracture zone are set to $14,16,18,20,22,24$, and $26 \mathrm{~m}$, which are $L=2,3,4,5,6,7$, and $8 \mathrm{~m}$ beyond the two ends of the fracture zone, respectively. Under those conditions, the changes in the subsidence and convergence of surrounding rocks in, and around, the fracture zone under different lengths of

401 advanced support were studied.

As seen from Figs 18 and 19, deformation at elements E1 to E10 and E21 to E30 in the vault in the vicinity of the fracture zone, as well as at elements F1 to F10 and F21 to F30 in the sidewalls all decrease slightly with certain regularity for given support parameters. In comparison, an apparent attenuation is seen in the deformation of elements E11 to E20 in the vault and F11 to F20 in the sidewalls in the section of the fracture zone: both the subsidence and convergence of surrounding rocks are much reduced as the length of advanced support increases from $14 \mathrm{~m}$ to 20 $\mathrm{m}$; with the further increase of the length from $20 \mathrm{~m}$ to $26 \mathrm{~m}$, the subsidence and convergence of surrounding rocks change only marginally. This indicates that for a fracture zone with a width of $10 \mathrm{~m}$, it is recommended to set the length of advanced support to $20 \mathrm{~m}$ by comprehensively considering the safety and stability of surrounding rocks and the construction efficiency (i.e., it is best to use a length of advanced support that is twice the width of the fracture zone).

\subsection{Damage to rock surrounding the fracture zone under excavation footages behind the} zone

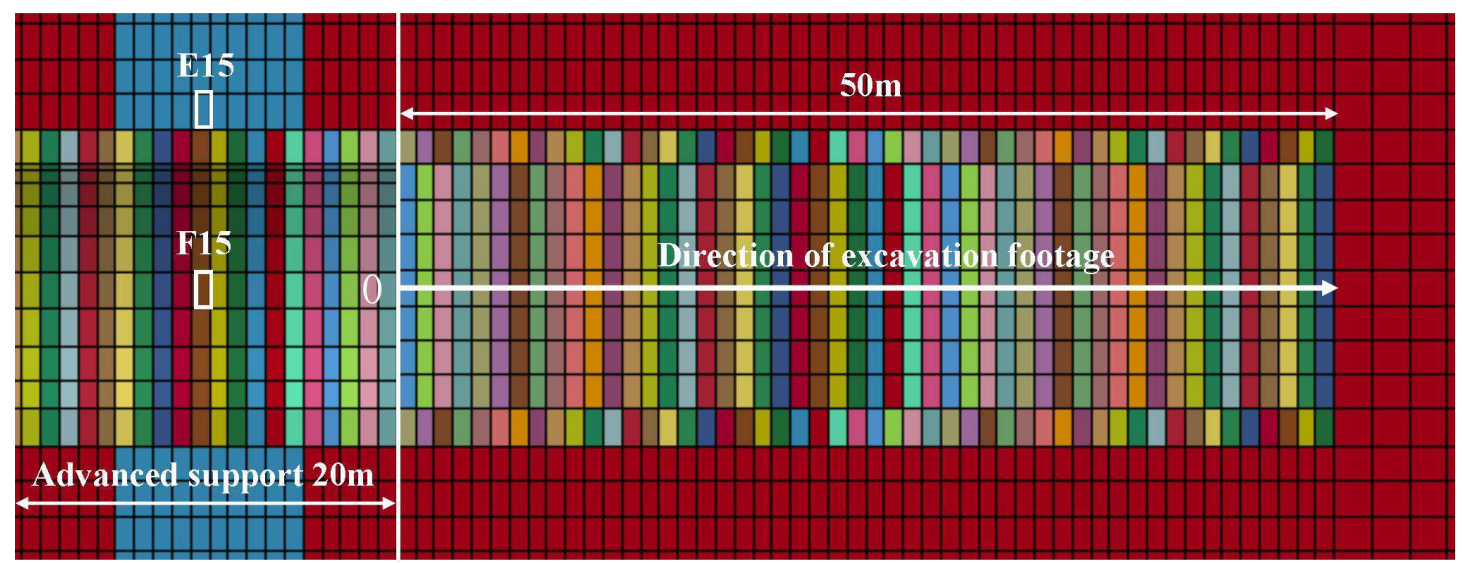

Fig. 20 Excavation of rock mass behind the fracture zone

Taking the parameters of material No. 4 for the advanced support (Section 5.2.1) and a length of advanced support of $20 \mathrm{~m}$ as the benchmark, the tunnel is excavated uninterruptedly for $50 \mathrm{~m}$ 
from the position $5 \mathrm{~m}$ behind the fracture zone (Fig. 20). The numerical calculation and analysis were conducted at excavation footages of 1,2 , and $3 \mathrm{~m} / \mathrm{d}$, respectively, to study deformations of elements E15 in the vault and F15 in the sidewall (both within the fracture zone), under different excavation footages.

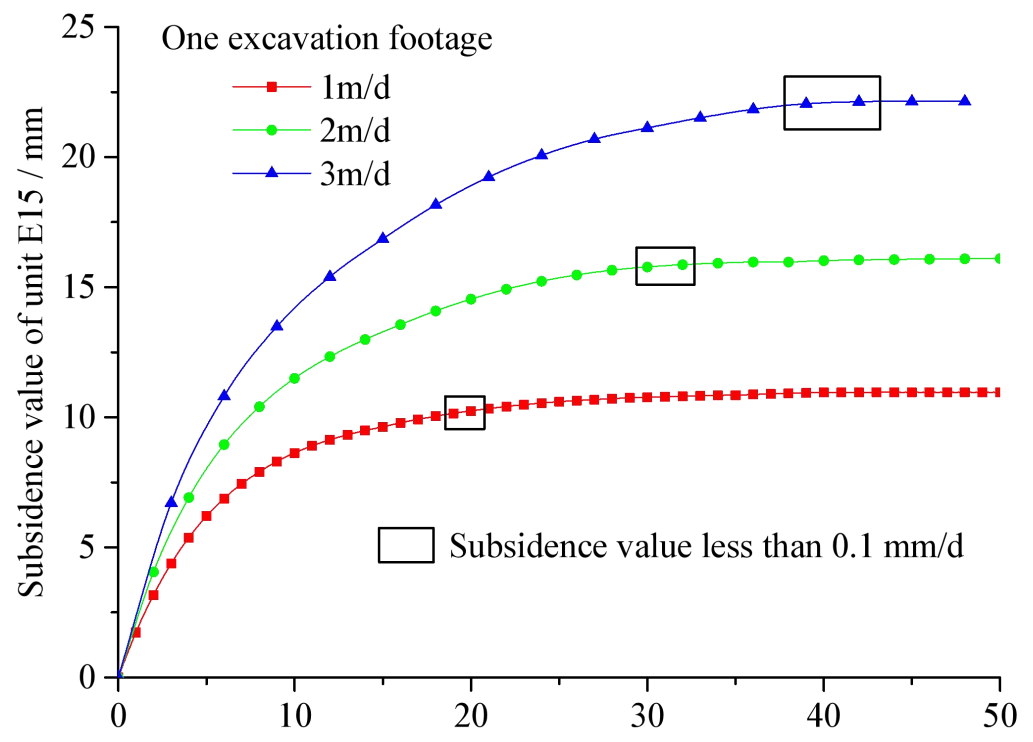

Footage length / $\mathrm{m}$

Fig. 21 Calculated subsidence of surrounding rocks in the vault under different excavation footages

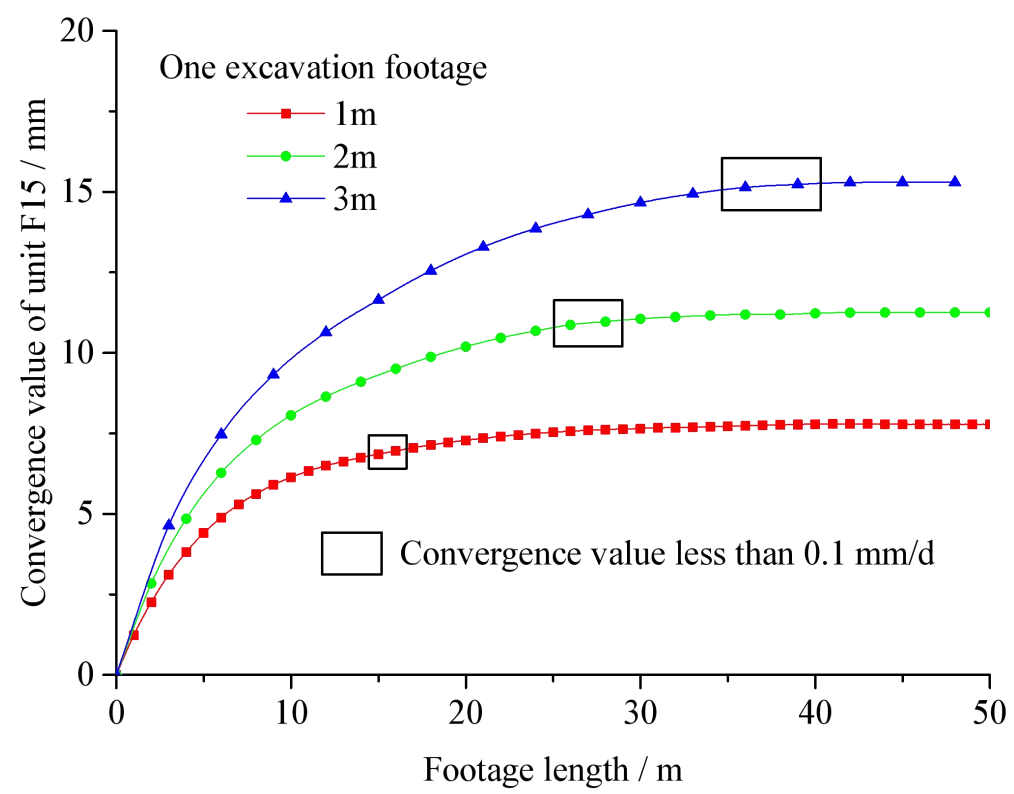

Fig. 22 Calculated convergence of surrounding rocks in the sidewalls under different excavation footages 
deformation of surrounding rocks of less than $0.1 \mathrm{~mm}$ as a criterion for judging stability, during the excavation at $1 \mathrm{~m} / \mathrm{d}$, the rate of subsidence of element E15 falls to below $0.1 \mathrm{~mm} / \mathrm{d}$ after excavation over a length of 19 to $20 \mathrm{~m}$; while the rate of convergence of element F15 is less than $0.1 \mathrm{~mm} / \mathrm{d}$ after excavation over 15 to $16 \mathrm{~m}$. If the tunnel is excavated at $2 \mathrm{~m} / \mathrm{d}$, the rate of subsidence of element E15 and the rate of convergence of F15 fell to a value below $0.1 \mathrm{~mm} / \mathrm{d}$ separately after excavation over 30 to $32 \mathrm{~m}$ and 26 to $28 \mathrm{~m}$. At an excavation footage of $3 \mathrm{~m} / \mathrm{d}$, the rate of subsidence of element E15 fell to less than $0.1 \mathrm{~mm} / \mathrm{d}$ after excavation over 39 to $42 \mathrm{~m}$, while the rate of convergence of element F15 fell to this level after excavation over 36 to $39 \mathrm{~m}$. In general, the subsidence is larger than the convergence of the surrounding rocks, and the latter is about 0.7 times the former, therefore, the subsidence should be used to judge the stability of the surrounding rocks, according to which the excavation footage can be changed. When the tunnel is excavated over $30 \mathrm{~m}$, the excavation footage can be increased from $1 \mathrm{~m} / \mathrm{d}$ to $2 \mathrm{~m} / \mathrm{d}$, and furthermore to $3 \mathrm{~m} / \mathrm{d}$ after excavation over $39 \mathrm{~m}$.

\section{Conclusion}

This research demonstrates an engineering case-study in which the excavation of a deep tunnel through a fracture zone induced deformation and failure of surrounding rocks. Numerical simulation and analysis were conducted throughout the excavation of the tunnel through the fracture zone as well to control the deformations therein. The following conclusions can be drawn:

(1) If there is a fracture zone on the excavation path of a tunnel ahead, the rate of deformation of the rocks surrounding the tunnel section ahead of the fracture zone tends to increase at first, then decrease, with an inflection point in the deformation curve. This inflection point can only be observed on the deformation curves of exposed rock surrounding a tunnel section far from the fracture zone, however, as the rock surrounding the tunnel near the fracture zone have undergone large deformation early in the process, no inflection point is observed after exposure of that rock. The deformation profiles of surrounding rocks at different locations can also be used to estimate whether a fracture zone lies ahead or not.

(2) When the strength of materials used to form advanced supports is 1.15 times that of the rock surrounding the tunnel and the length of advanced support is twice the width of the fracture zone, the deformation of surrounding rocks can be safely controlled. In addition, the convergence is about two-thirds to three-quarters of the subsidence of the surrounding rock. 
(3) With the increase in the excavation length behind the fracture zone, the final deformation of surrounding rocks in the fracture zone at the excavation rate of $1 \mathrm{~m} / \mathrm{d}$ is about two-thirds that at $2 \mathrm{~m} / \mathrm{d}$ and half that at $3 \mathrm{~m} / \mathrm{d}$. In addition, as the deformation of the surrounding rock stabilizes, the excavated length at $1 \mathrm{~m} / \mathrm{d}$ is also about two-thirds that at $2 \mathrm{~m} / \mathrm{d}$ and half that at $3 \mathrm{~m} / \mathrm{d}$.

\section{Author Contributions statement}

Junhong Huang: Conceptualization, Formal analysis, Writing - review \& editing, Funding acquisition. Guang Zhang: Data curation, Methodology. Yi Luo: Writing - original draft, Project administration, Formal analysis, Funding acquisition. Shaohua Hu: Investigation, Supervision. Hangli Gong: Prepared figures 8-22. Xinping Li: Prepared figures 1-7, Funding acquisition. Xin Liu: Validation.

\section{Competing Interests statement}

We declare that the authors have no competing interests as defined by Nature Research, or other interests that might be perceived to influence the results and/or discussion reported in this paper.

\section{Acknowledgments}

This work was supported by the Fundamental Research Funds for the National Natural Science Foundation of China (51779197, 51979208, 51774222), the Postdoctoral Innovation Research Post of Hubei Province of China (20201jb001), the Hubei Key Laboratory of Roadway Bridge and Structure Engineering (Wuhan University of Technology) (No. DQJJ201904), the Fundamental Research Funds for the Central Universities (WUT: 2019IVA098).

\section{References}

[1] Li Qiyue, Wei Xinao; Zheng Jing; Zhang Jianqiu; Zhao Xinhao. Study and Application of Profile Control for Full Section Excavation of Large Section Tunnel in Grad. Journal of

[3] Wang Yaqiong; Chang Hongtao; Wang Jianyu; Shi Xiaoli; Qiu Junling. Countermeasures to treat collapse during the construction of road tunnel in fault zone: a case study from the 

464.

[4] Y Xue; B Zhou; Z Wu; H Gao; D Qiu; G Li; K Fu. Mechanical properties of support forms for fault fracture zone in subsea tunnel. Soil Mechanics and Foundation Engineering, 2020, 56(6): 436-444.

[5] Su Haijian; Jing Hongwen; Zhao Honghui; Yu Liyuan; Wang Yingchao. Strength degradation and anchoring behavior of rock mass in the fault fracture zone. Environmental Earth Sciences, 2017, 76(4): 1-11

[6] Zeng Yi, Zhang Junwei, Li Jinping, Quan Xiaojuan. Stability analysis of tunnel rock mass under curtain grouting construction. Electronic Journal of Geotechnical Engineering, 2013,

[7] Zhou Jixue; Luo Yi; Li XinPing; Guo Yunhua; Liu Tingting. Numerical evaluation on

[10] Huang Xing; Liu Quansheng; Shi Kai; Pan Yucong; Liu Jianping. Application and prospect of hard rock TBM for deep roadway construction in coal mines. Tunneling \& Underground Space Technology, 2018, 73: 105-126.

[11] Jiang Yue; Zhou Hui; Lu Jingjing; Gao Yang; Zhang Chuanqing; Chen Jun. Analysis of stress evolution characteristics during TBM excavation in deep buried tunnels(Article). Bulletin of Engineering Geology and the Environment, 2019, 78(7): 5177-5194.

[12] Zheng Y.L; Zhang Q.B; Zhao J. Challenges and opportunities of using tunnel boring machines in mining. Tunneling \& Underground Space Technology, 2016, 57: 287-299.

[13] WD Ortlepp; TR Stacey. Rockburst mechanisms in tunnels and shafts. Tunneling and Underground Space Technology, 1994, 9(1): 59-65. 
[14] Rong Lu; Fengshan Ma; Jie Zhao; Jianbo Wang; Guilin Li; Bing Dai. Analysis and monitoring of small-scale rock fracture zone deformation and shaft failure in a metal mine. Advances in Civil Engineering, 2020, 8879258.

[15] Chen Ziquan; He Chuan; Xu Guowen; Ma Gaoyu; Yang Wenbo. Supporting mechanism and mechanical behavior of a double primary support method for tunnels in broken phyllite under high geo-stress: a case study. Bulletin of Engineering Geology \& the Environment, 2019, 78(7): 5253-5267.

[16] Zhan Qinjian; Zheng Xigui; Du Jiping; Xiao Tan. Coupling instability mechanism and joint control technology of soft-rock roadway with a buried depth of 1336m. Rock Mechanics \& Rock Engineering, 2020, 53(5): 2233-2248.

[17] Rubin Wang; Bo Xu; Yu Wan; Huanling Wang; Wei Wang; Qingxiang Meng. Characteristics of unloading damage and permeability evolution of sandstone under hydro-mechanical coupling. European Journal of Environmental and Civil Engineering, 2020.

[18] Ding Xiuli; Niu Xinqiang; Pei Qitao; Huang Shuling; Zhang Yuting; Zhang, Cunhui. Stability of large underground caverns excavated in layered rock masses with steep dip angles: a case study. Bulletin of Engineering Geology \& the Environment, 2019, 78(7): 5101-5133.

[19] Barla G. Full-face excavation of large tunnels in difficult conditions. Journal of Rock Mechanics and Geotechnical Engineering, 2016, 8(3): 294-303.

[20] Zilan Zhong; Zhen Wang; Mi Zhao; Xiuli Du. Structural damage assessment of mountain tunnels in fault fracture zone subjected to multiple strike-slip fault movement. Tunnelling and Underground Space Technology, 2020, 104: 103527.

[21] Maria Alcione Lima Celestino; Tiago Siqueira de Miranda; Gorki Mariano; Marcio de Lima Alencar; Bruno Raphael Barbosa Melo de Carvalho; Thiago da Cruz Falcão; João Gabriel Topan; José Antonio Barbosa; Igor Fernandes Gomes. Fault damage zones width: Implications for the tectonic evolution of the northern border of the Araripe Basin, Brazil, NE Brazil. Journal of Structural Geology, 2020, 138: 104116.

[22] Xie Shengrong; Pan Hao; Zeng Junchao; Wang En; Chen Dongdong; Zhang Tao; Peng Xuejiao; Yang Junhui; Chen Feng; Qiao Shunxing. A case study on control technology of surrounding rock of a large section chamber under a 1200-m deep goaf in Xingdong coal mine, China. Engineering Failure Analysis, 2019, 104: 112-125. 
[23] Huo Bingjie; Tai Yang; Meng Xiangbin; Kuang Tiejun. Deformation and failure mechanism of full seam chamber with extra-large section and its control technology. Open Geosciences, 2020, 12(1): 390-405.

[24] Zhili Su; Wenbing Xie; Shengguo Jing; Xingkai Wang; Qingteng Tang. Fracturing of the soft rock surrounding a roadway subjected to mining at kouzidong coal mine. Advances in Civil Engineering, 2020, 6858643.

[25] Huang Feng; Wu Chuangzhou; Ni Pengpeng; Wan Guoqing; Zheng Aichen; Jang Bo-An; Karekal Shivakumar. Experimental analysis of progressive failure behavior of rock tunnel with a fault zone using non-contact DIC technique. International Journal of Rock Mechanics \& Mining Sciences, 2020, 132: 104355

[26] Li Guang; Ma Fengshan; Guo Jie; Zhao Haijun. Deformation Characteristics and Control Method of Kilometer-Depth Roadways in a Nickel Mine: A Case Study. Applied Sciences, 2020, 10(11): 3937.

[27] Xie Zhengzheng; Zhang Nong; Feng Xiaowei; Liang Dongxu; Wei Qun; Weng Mingyue. Investigation on the evolution and control of surrounding rock fracture under different supporting conditions in deep roadway during excavation period. International Journal of Rock Mechanics \& Mining Sciences, 2019, 123: 104122.

[28] Cheng Cheng; Zhao Wen; Qi Diyang; Han Jianyong; Jia Pengjiao; Chen Yang; Bai Qian. A case study on the stability of the shield excavation face in full-section coarse sand. Sustainable Cities and Society, 2019, 47: 101486.

[29] Lyu Xianzhou; Zhao Zenghui; Ma Qing; Wang Xiaojie; Gao Xiaojie. 2D semimodel of full-section anchorage in thick soft rock roadway. Shock and Vibration, 2018, 9853853.

[30] Shaohua Du; Diyuan Li; Bo Ruan; Genshui Wu; Bao Pan; Jinyin Ma. Deformation and fracture of circular tunnels under non-tectonic stresses and its support control. European Journal of Environmental and Civil Engineering, 2020.

[31] Jixue Zhou; Junhong Huang; Yi Luo; Xinping Li. Influence and evaluation of potential fractured zone by surrounding rockmass deformation during deep tunneling blasting excavation. 10th International Conference on Simulation and Modeling Methodologies, Technologies and Applications. 2020: 279-286.

[32] Panet M; Givet P D C; Guilloux A; Duc J L D G; Piraud J, Wong H T S D. The 
convergence-confinement method. AFTES-recommendations des Groupes de Travait, 2001.

581 [33] Panet M. Le calcul des tunnels par la méthode convergence-confinement. Presses ENPC, $582 \quad 1995$.

583 [34] Hoek E; Brown E T. The Hoek-Brown failure criterion - a 1998 update. Journal of Heuristics, $584 \quad 1988,16(2): 167-188$.

[35] Carranza-Torres C; Fairhurst C. Application of the convergence-confinement method of tunnel design to rock masses that satisfy the Hoek-Brown failure criterion. Tunnelling and Underground Space Technology, 2000, 15(2): 187-213.

[36] Sun Chuang; Zhang Xiangdong, Liu Jiashun. Application of strain softening model to tunnels based on Hoek-Brown strength criterion. Rock and Soil Mechanics, 2013(10): 2954-2960. (in Chinese)

[37] Zhao Kai; Bonini Mariacristina; Debernardi Daniele; Janutolo Michele; Barla Giovanni; Chen Guoxing. Computational modelling of the mechanised excavation of deep tunnels in weak rock. Computers and Geotechnics, 2015, 66: 158-171.

[38] Basarir H; Genis M; Ozarslan A. The analysis of radial displacements occurring near the face of a circular opening in weak rock mass. International Journal of Rock Mechanics and Mining Sciences, 2010, 47(5): 771-783.

[39] Institute of Rock and Soil Mechanics, Chinese Academy of Sciences. Report on the geostress test and deformation of surrounding rocks of the Daliang Tunnel on Gansu-Qinghai section of the Lanzhou-Xinjiang second double-track railway, 2012.

[40] Fang Qian; Su Wei; Zhang Dingli. Yu Fucai. Tunnel deformation characteristics based on on-site monitoring data. Chinese Journal of Rock Mechanics and Engineering, 2016, 603 


\section{Figures}

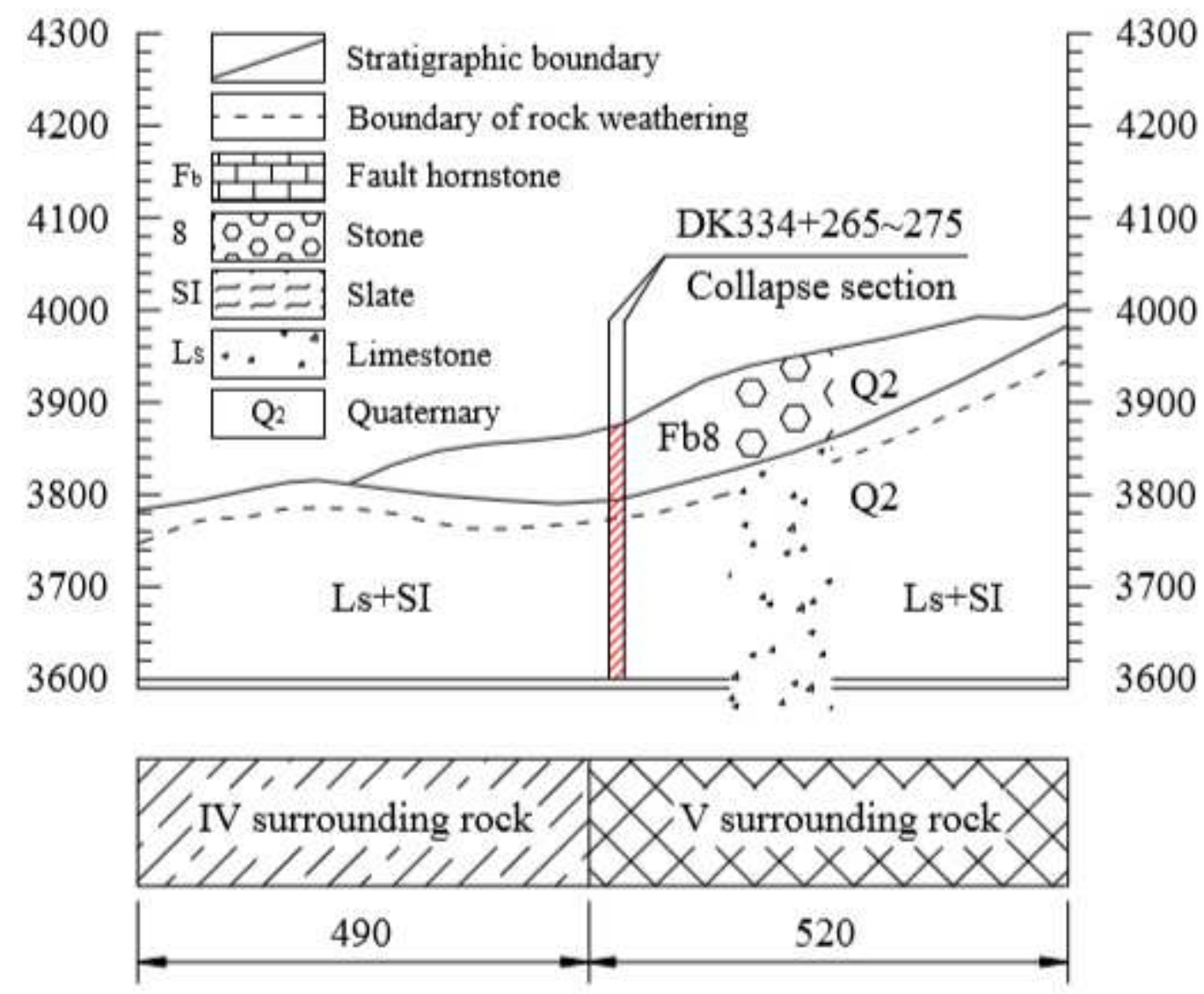

Figure 1

The longitudinal profile of the collapse zone in the Daliang Tunnel (unit: $\mathrm{m}$ ) 


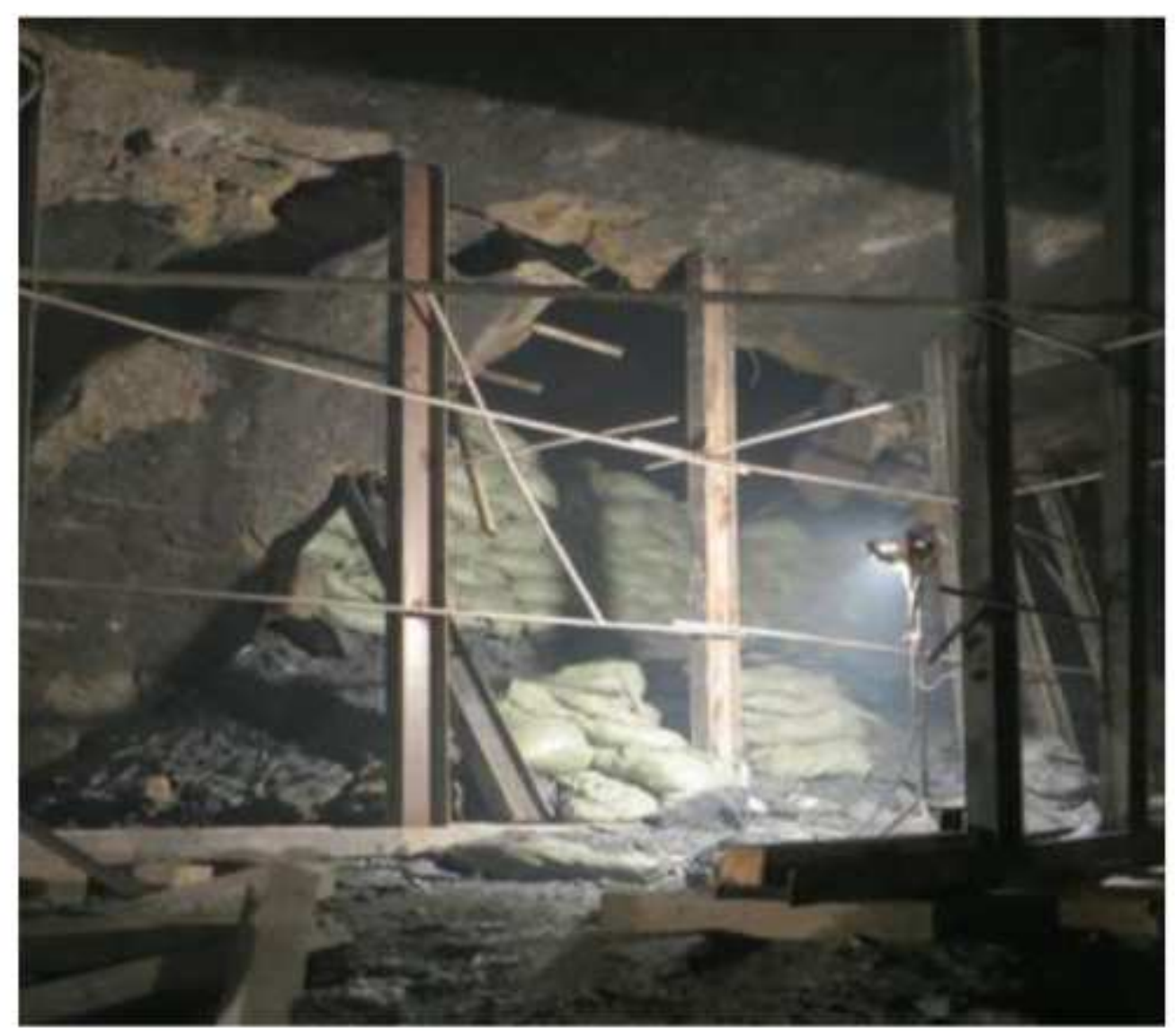

Figure 2

Collapse of the fracture zone 


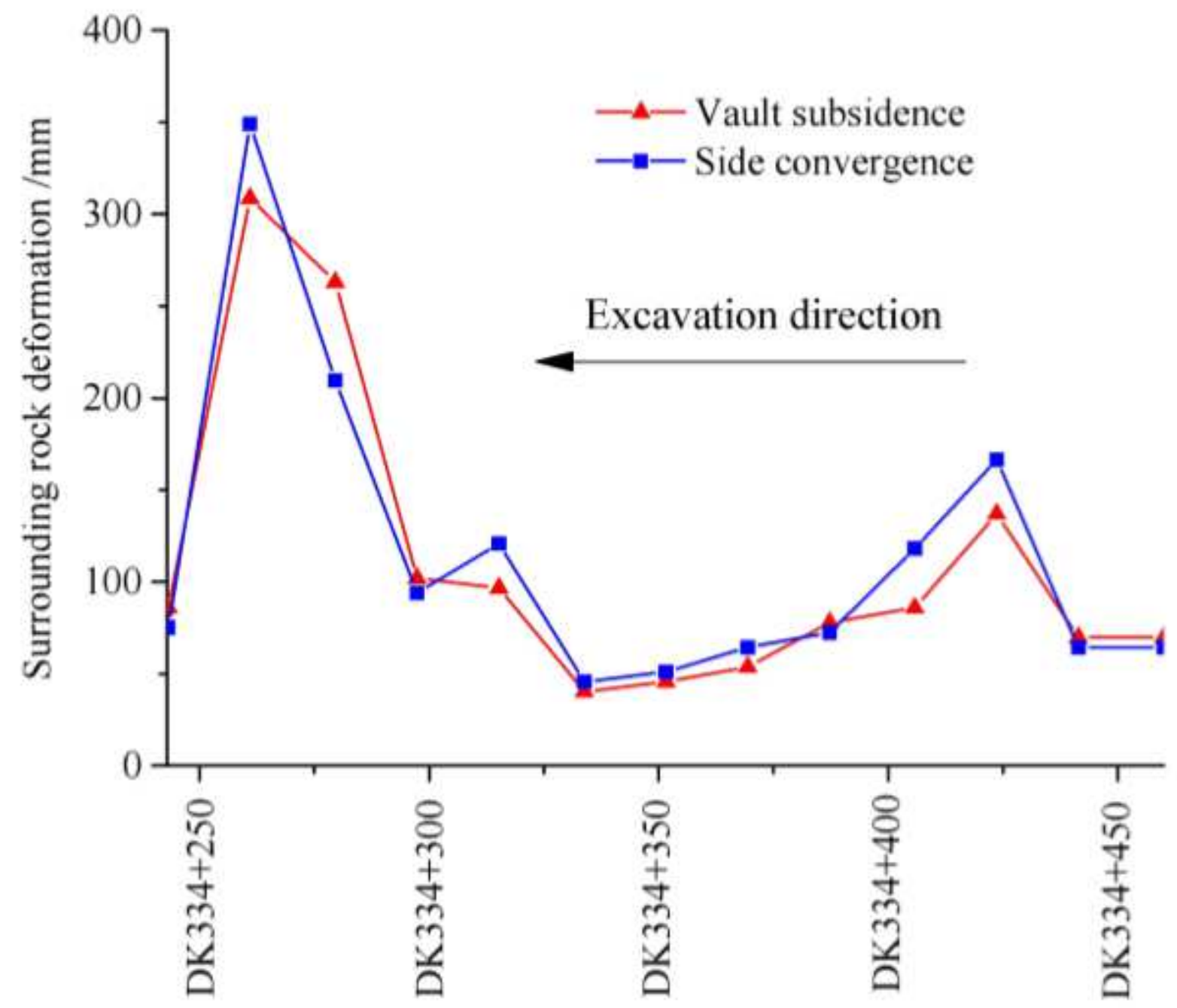

Figure 3

Monitoring results of cumulative deformation during the excavation 


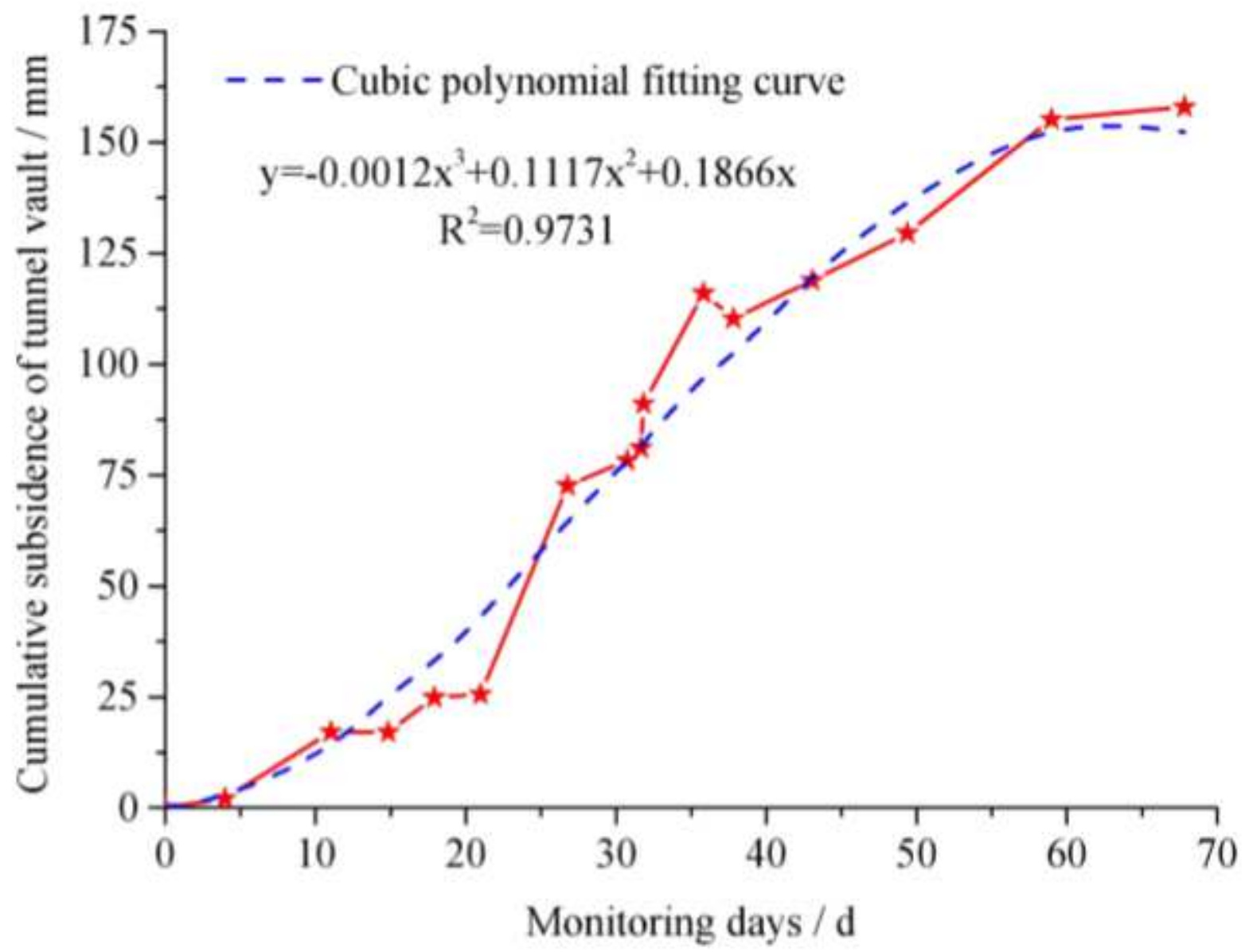

Figure 4

Statistical analysis of cumulative subsidence measured at different points

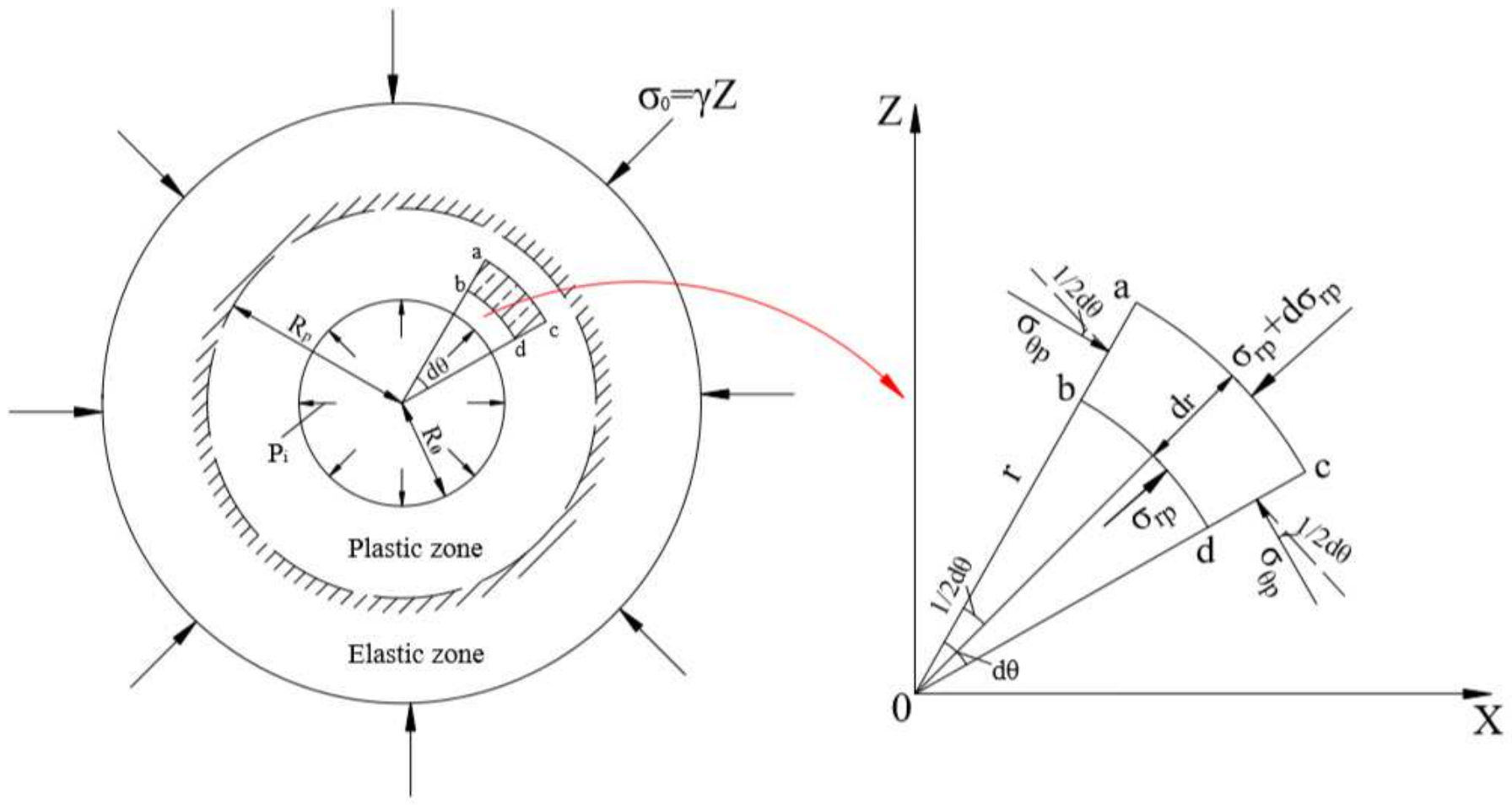


Figure 5

Analysis of the stress in the rock surrounding the plastic zone

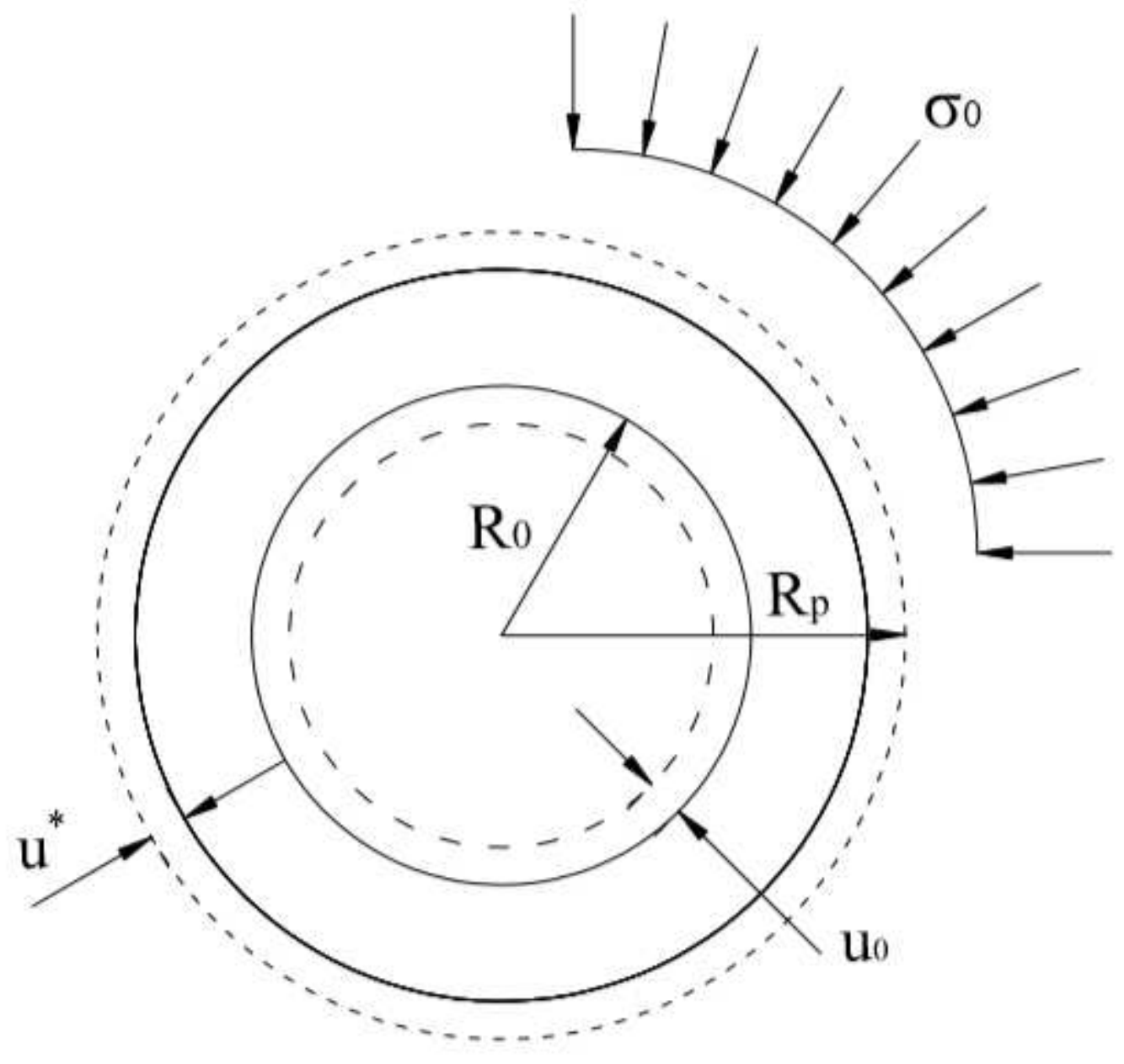

Figure 6

Radial displacement of surrounding rocks 


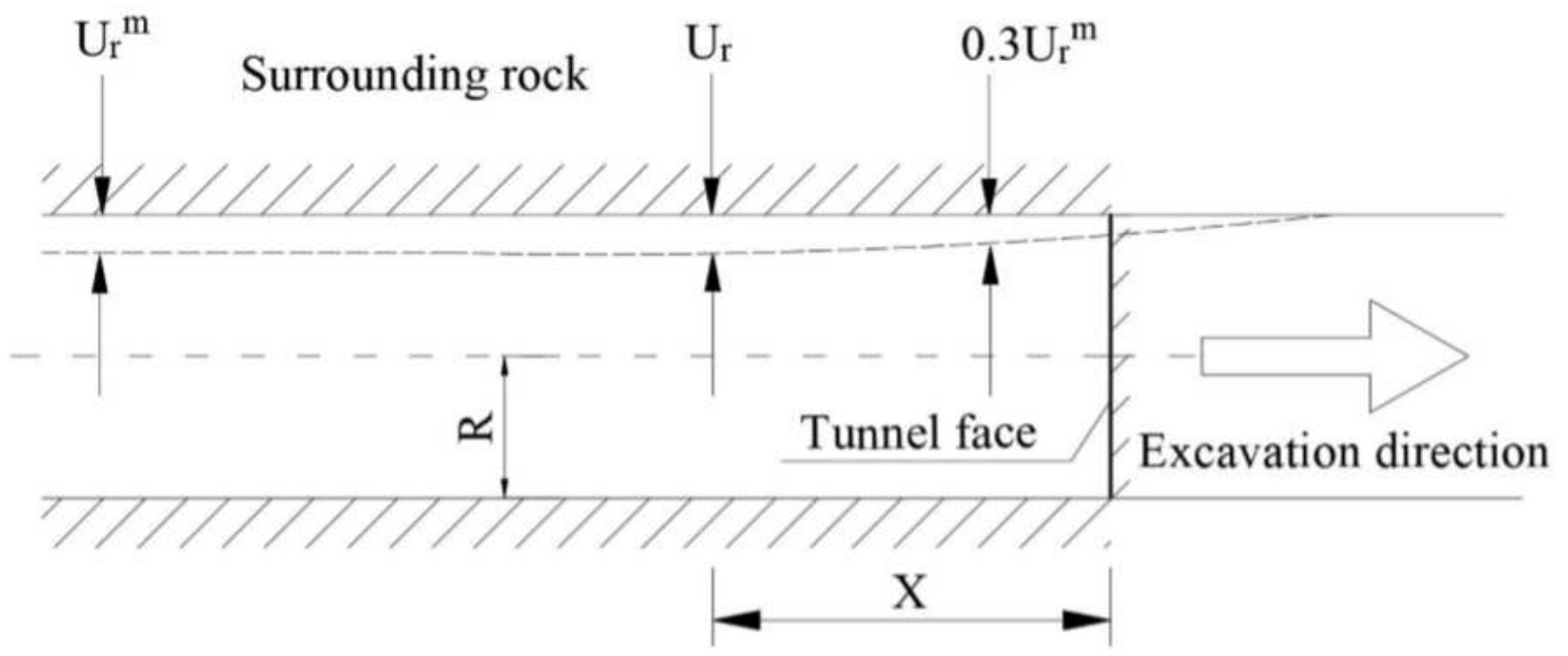

Figure 7

Numerical model of the profile of radial displacement along the tunnel axis
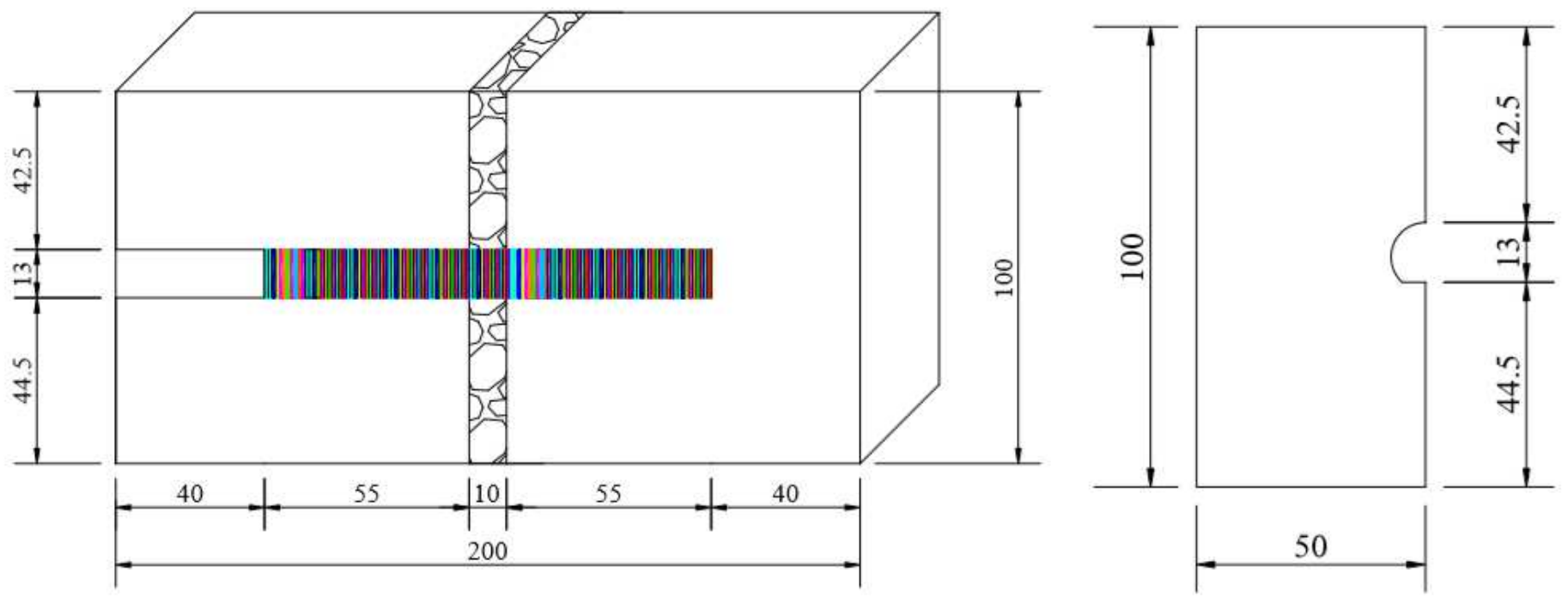

Figure 8

Dimensions of the numerical model (unit: $\mathrm{m}$ ) 


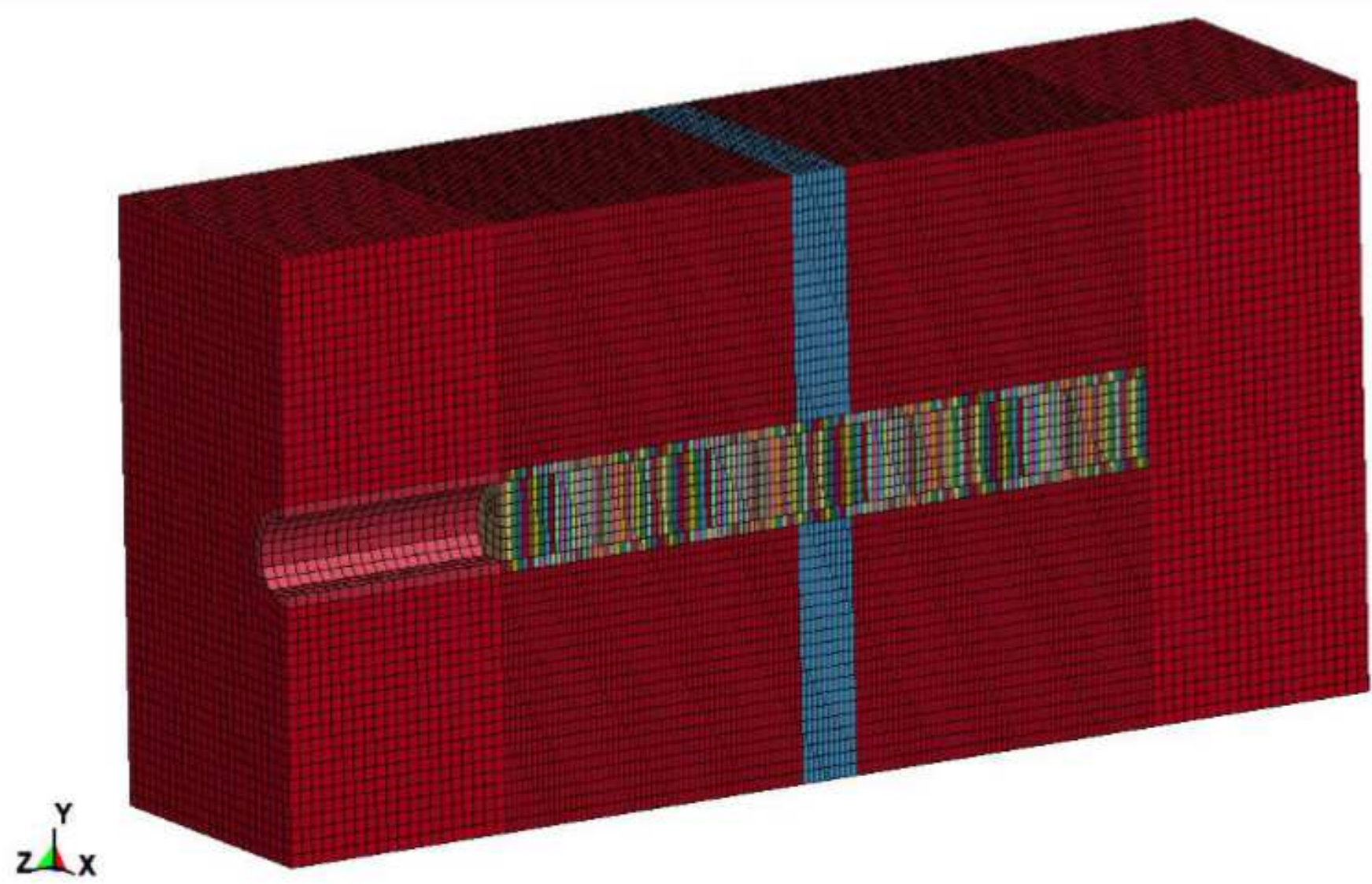

Figure 9

Finite-element mechanical model 


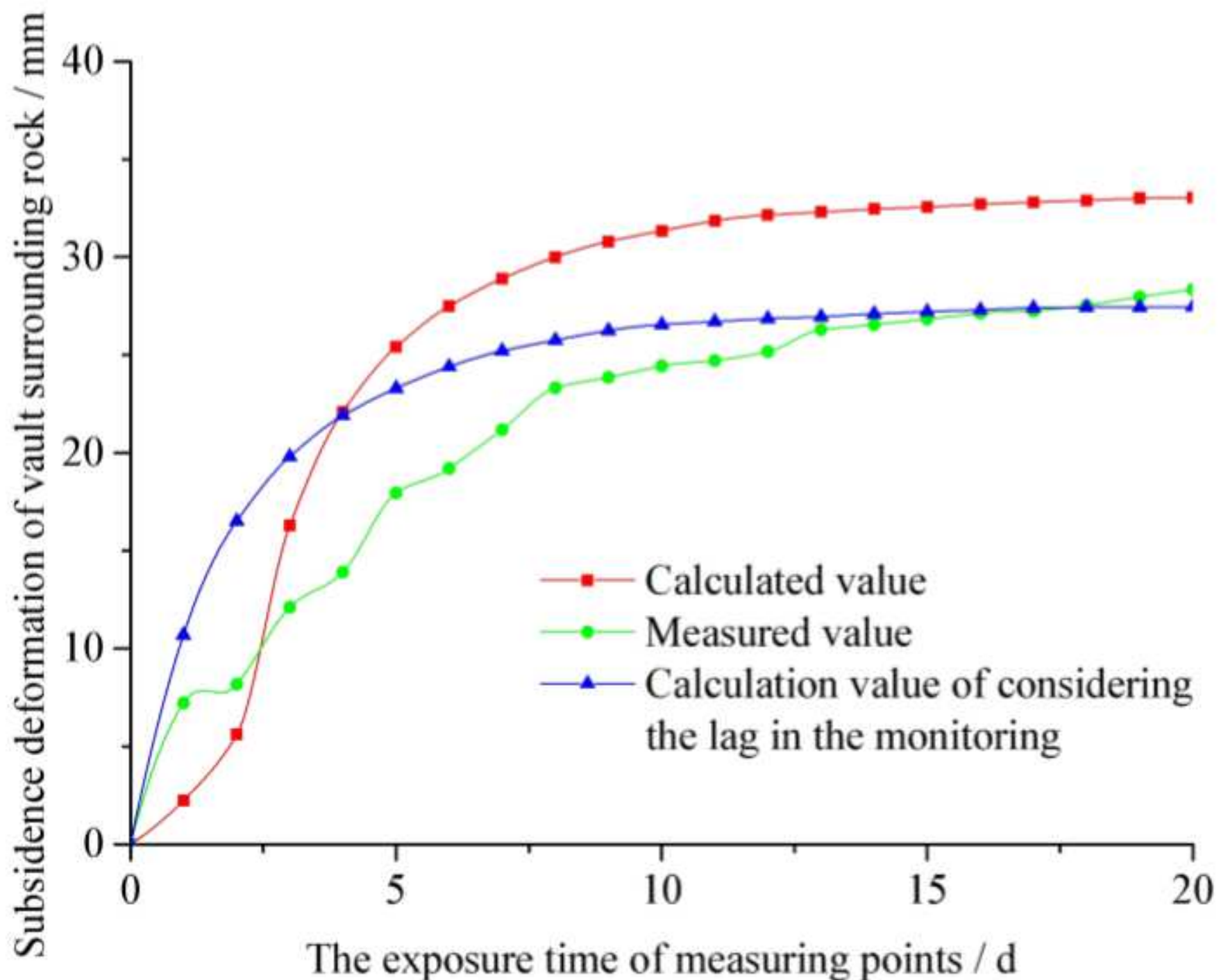

Figure 10

Data measured in the tunnel and numerically calculated deformation profiles for surrounding rocks

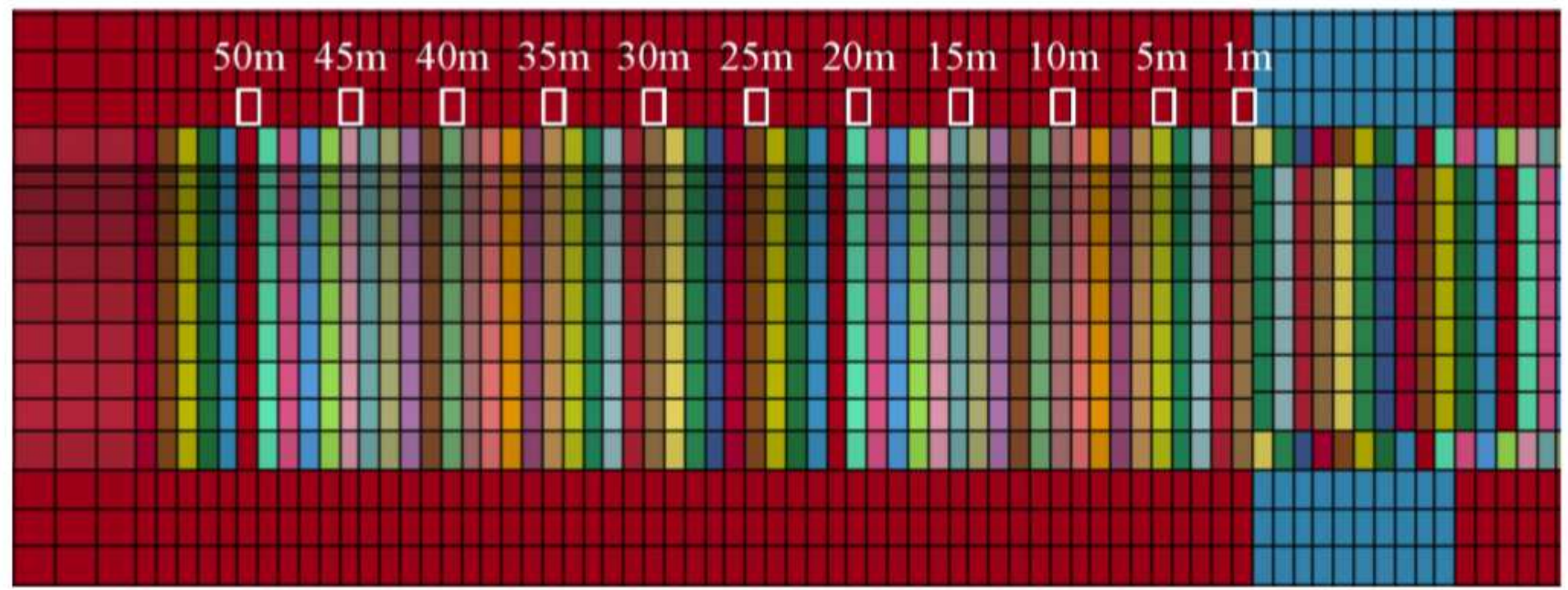


Figure 11

Layout of monitoring points in the rock surrounding the tunnel

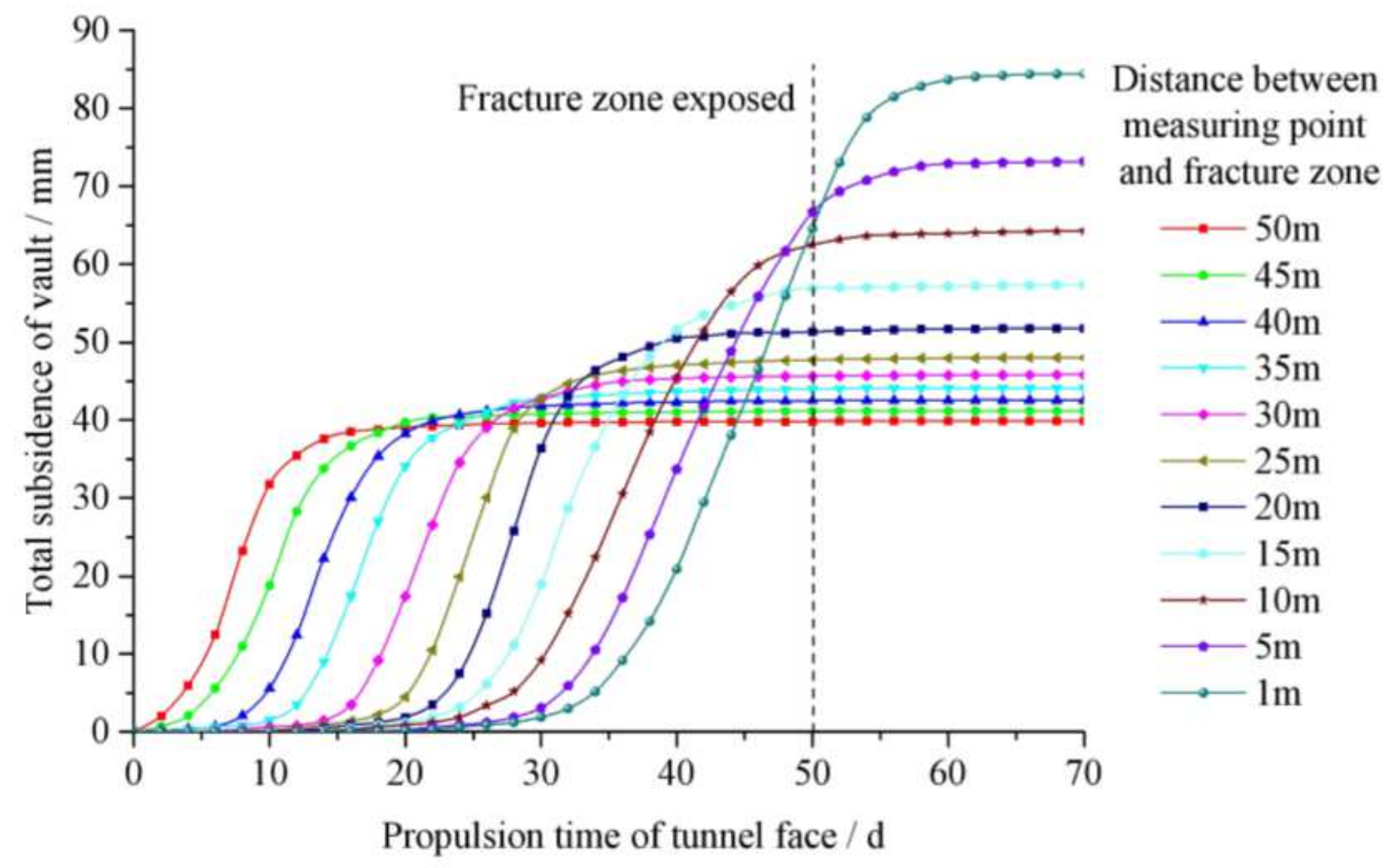

Figure 12

Calculated cumulative subsidence at different positions 


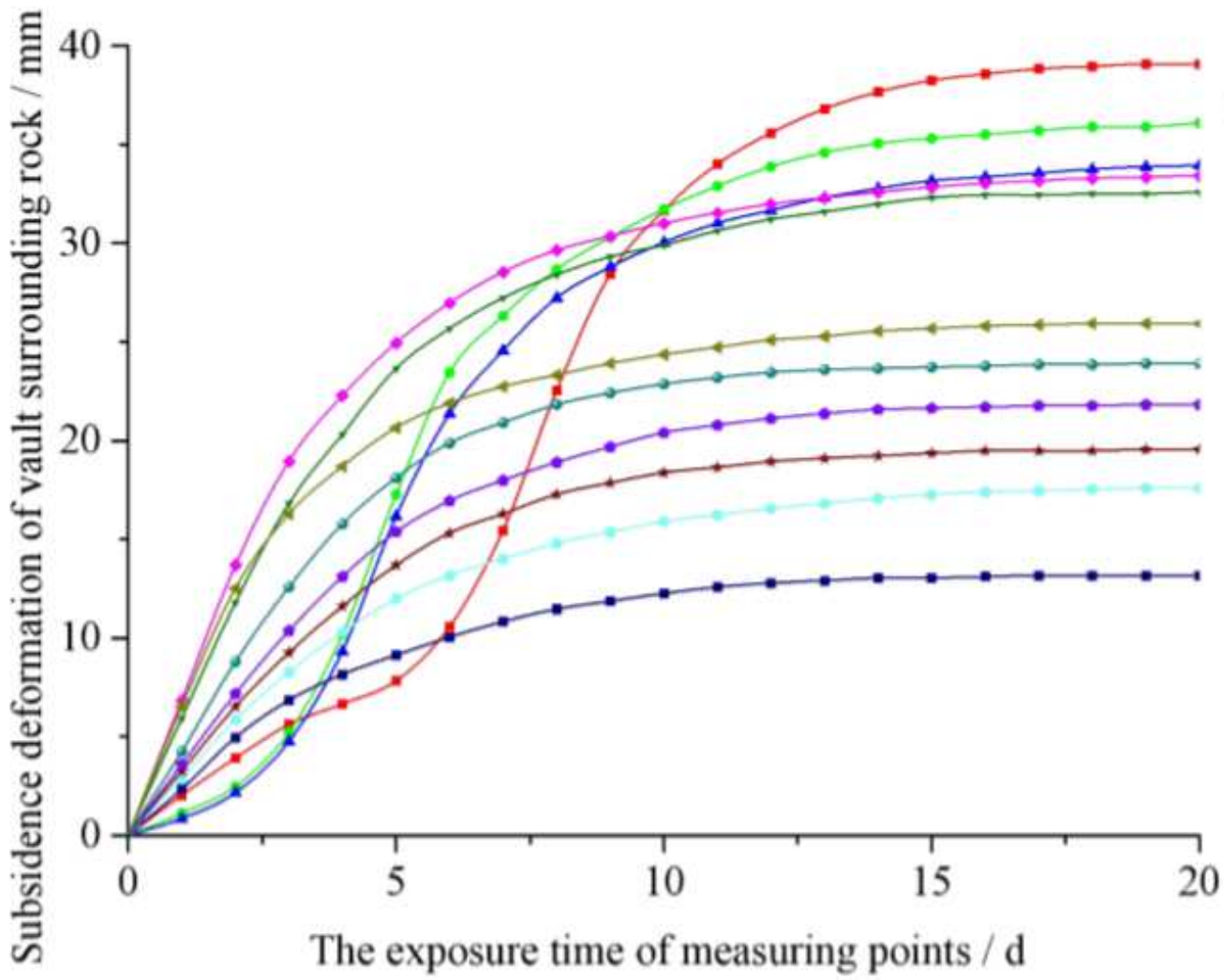

Distance between measuring point and fracture zone

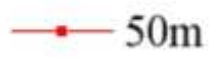

$\because 45 \mathrm{~m}$

$\longrightarrow 40 \mathrm{~m}$

$\longrightarrow 35 \mathrm{~m}$

$\longrightarrow 30 \mathrm{~m}$

$\longrightarrow 25 \mathrm{~m}$

$\rightarrow-20 \mathrm{~m}$

$15 \mathrm{~m}$

$\longrightarrow 10 \mathrm{~m}$

$\longrightarrow 5 \mathrm{~m}$

$\longrightarrow 1 \mathrm{~m}$

Figure 13

Calculated cumulative subsidence after exposure of monitoring points at different positions

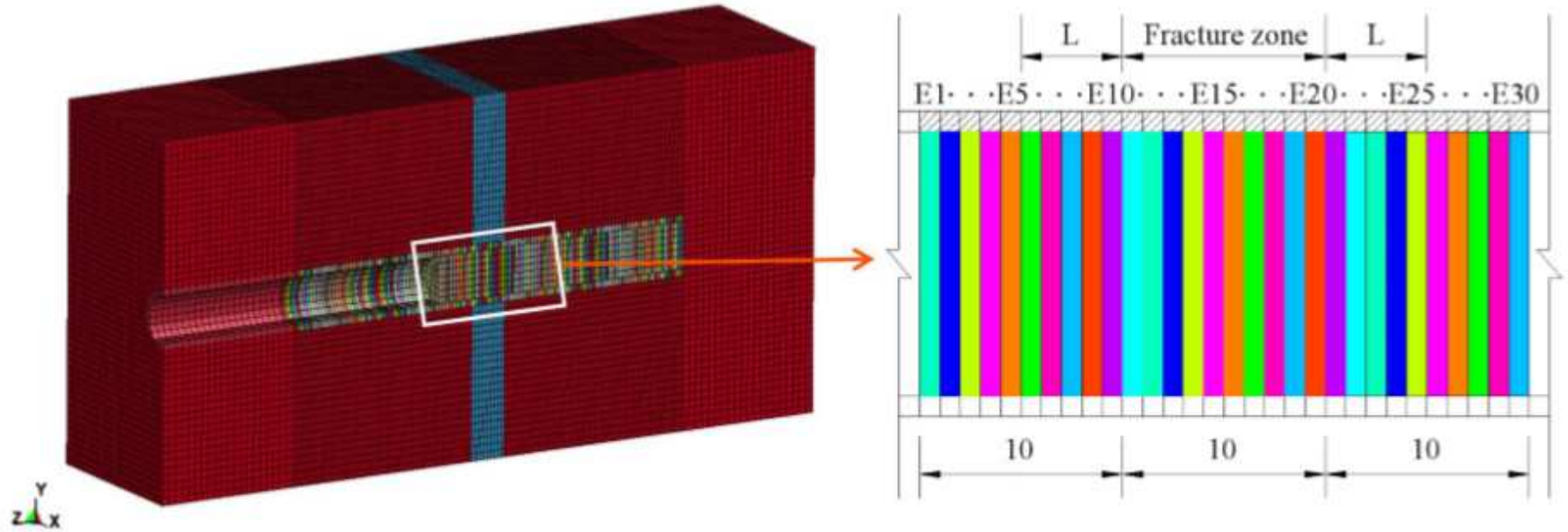

Figure 14

Surrounding rocks in, and around, the fracture zone before excavation 


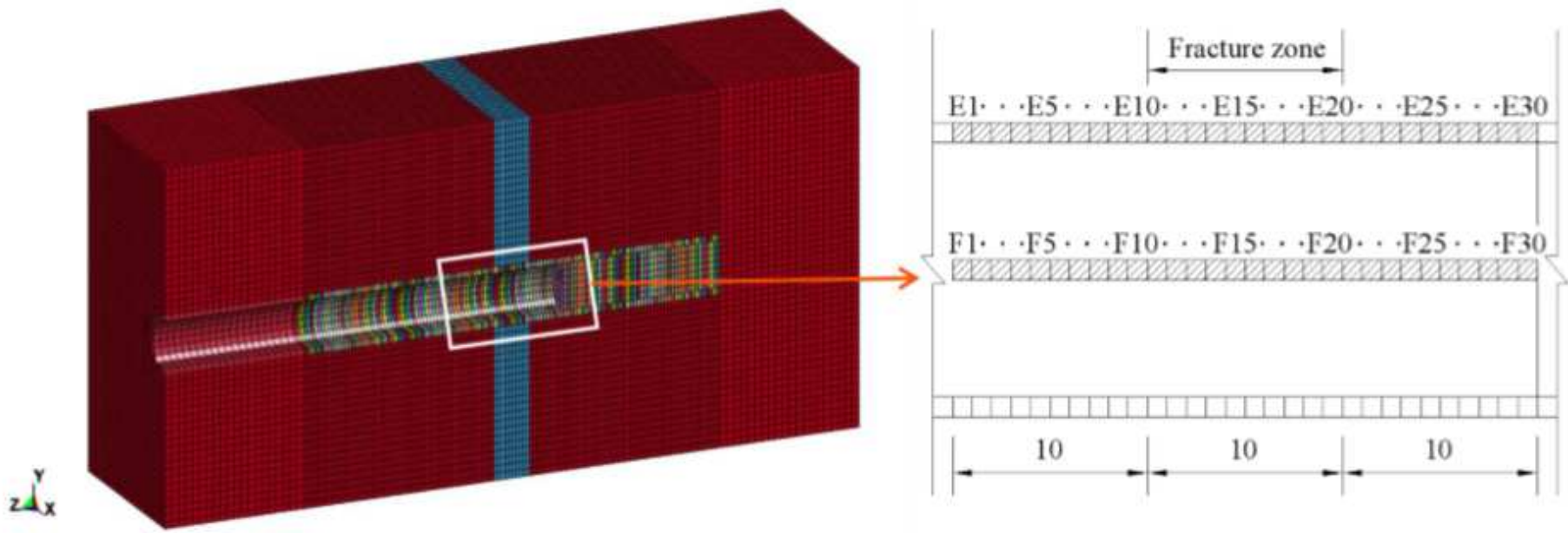

Figure 15

Surrounding rocks in, and around, the fracture zone after excavation

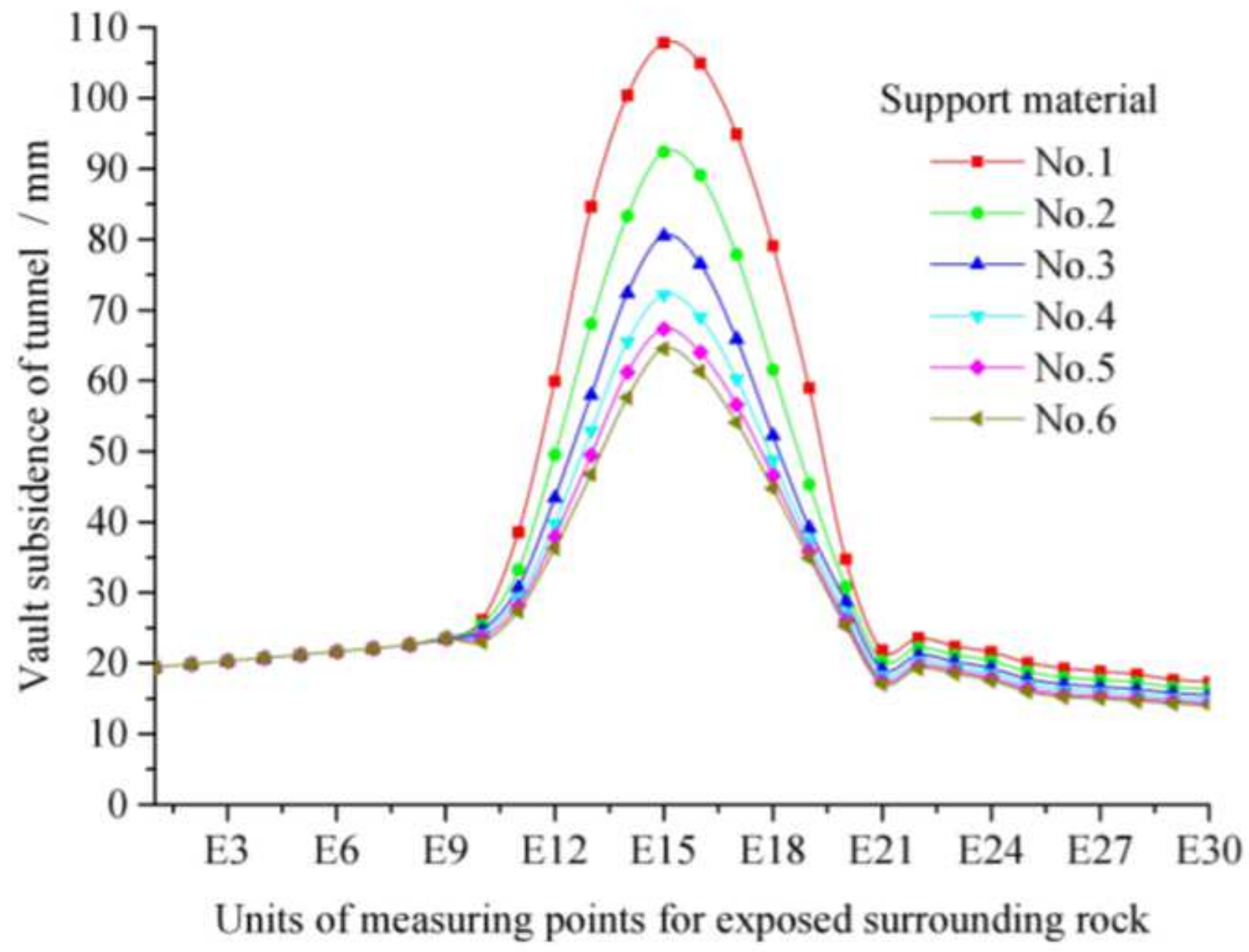

Figure 16 
Calculated subsidence of surrounding rocks in the vault under advanced support with materials of different properties

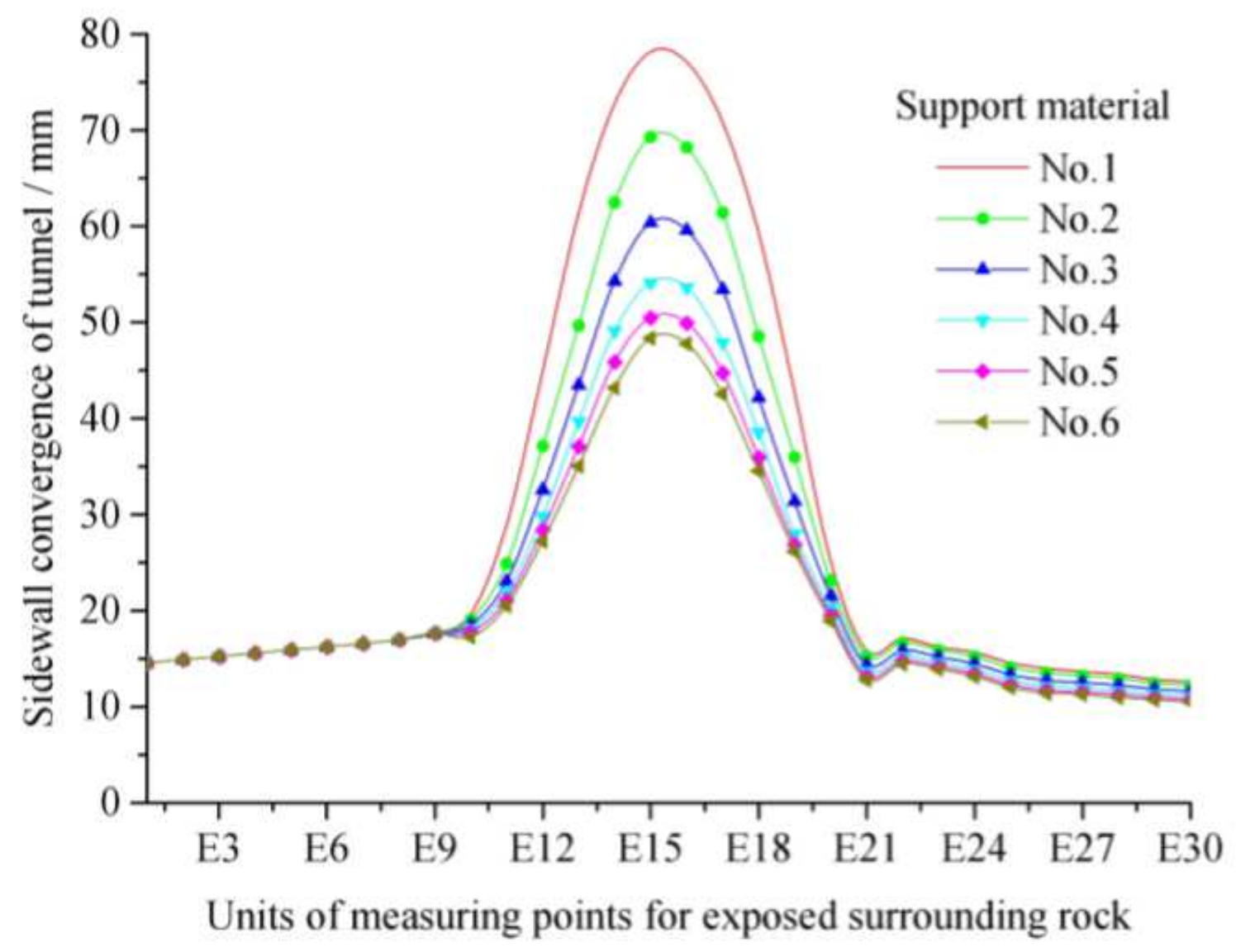

Figure 17

Calculated convergence of surrounding rocks under advanced support with materials of different properties 


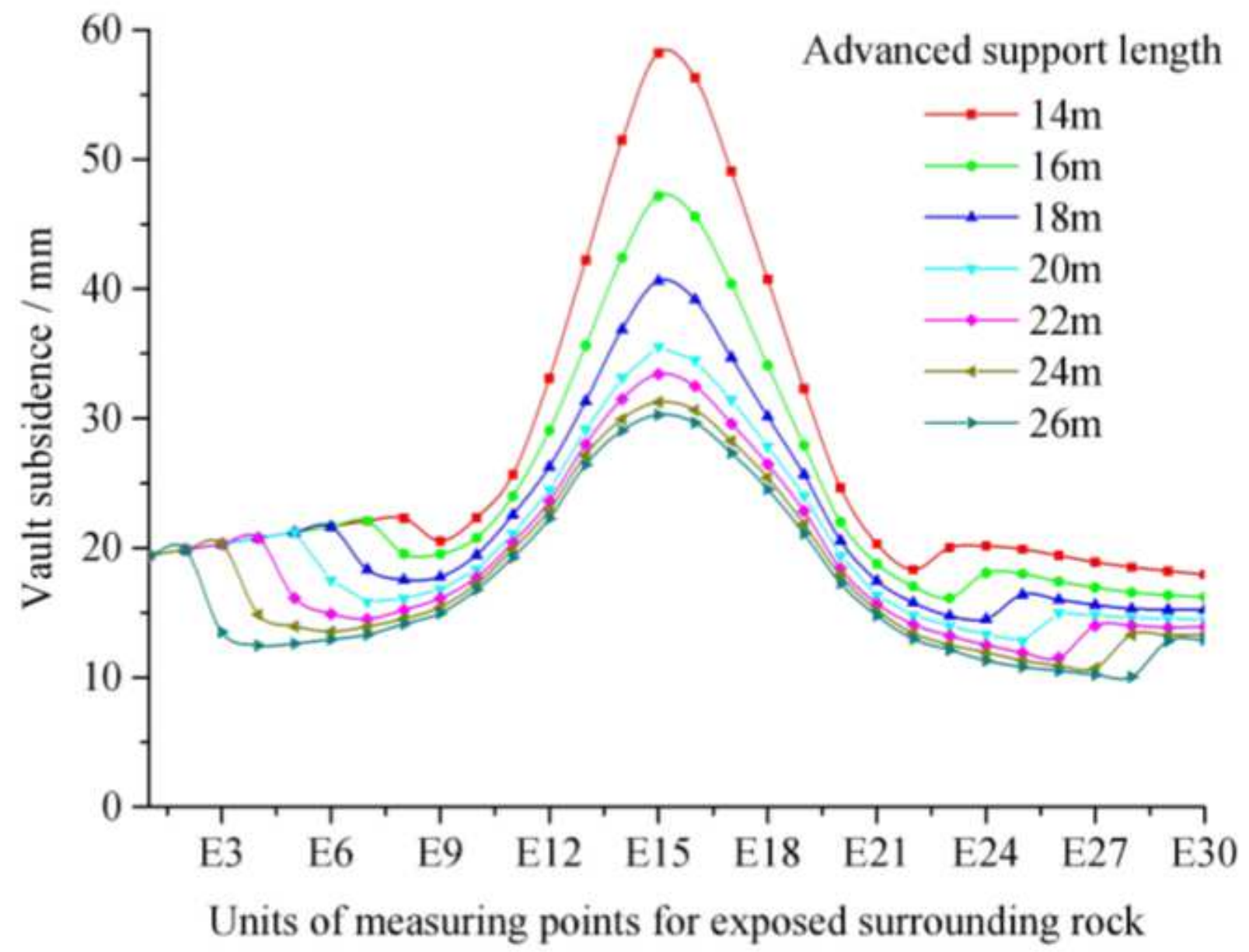

Figure 18

Calculated subsidence of surrounding rocks in the vault under different lengths of advanced support 


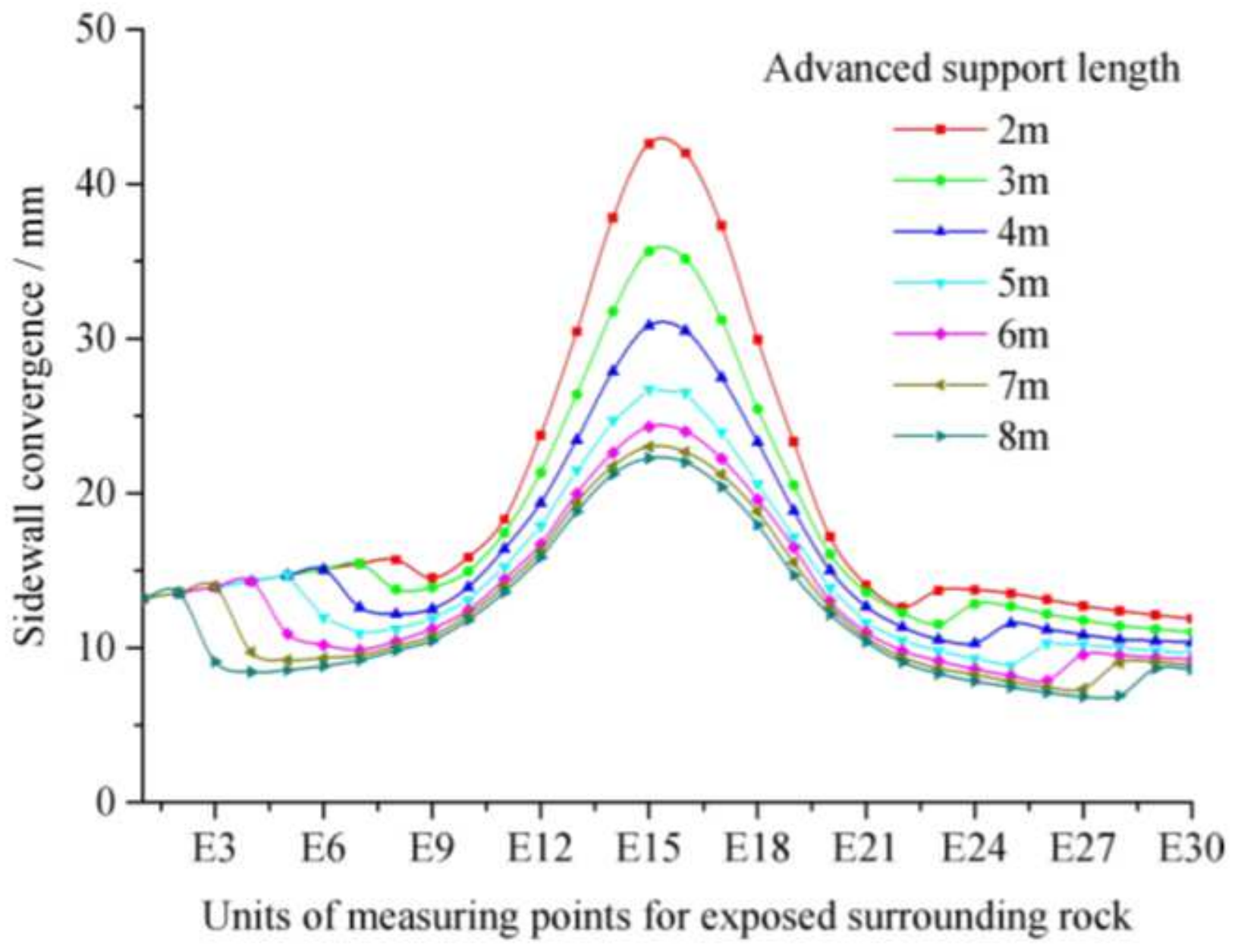

Figure 19

Calculated convergence of surrounding rocks in the sidewalls under different lengths of advanced support

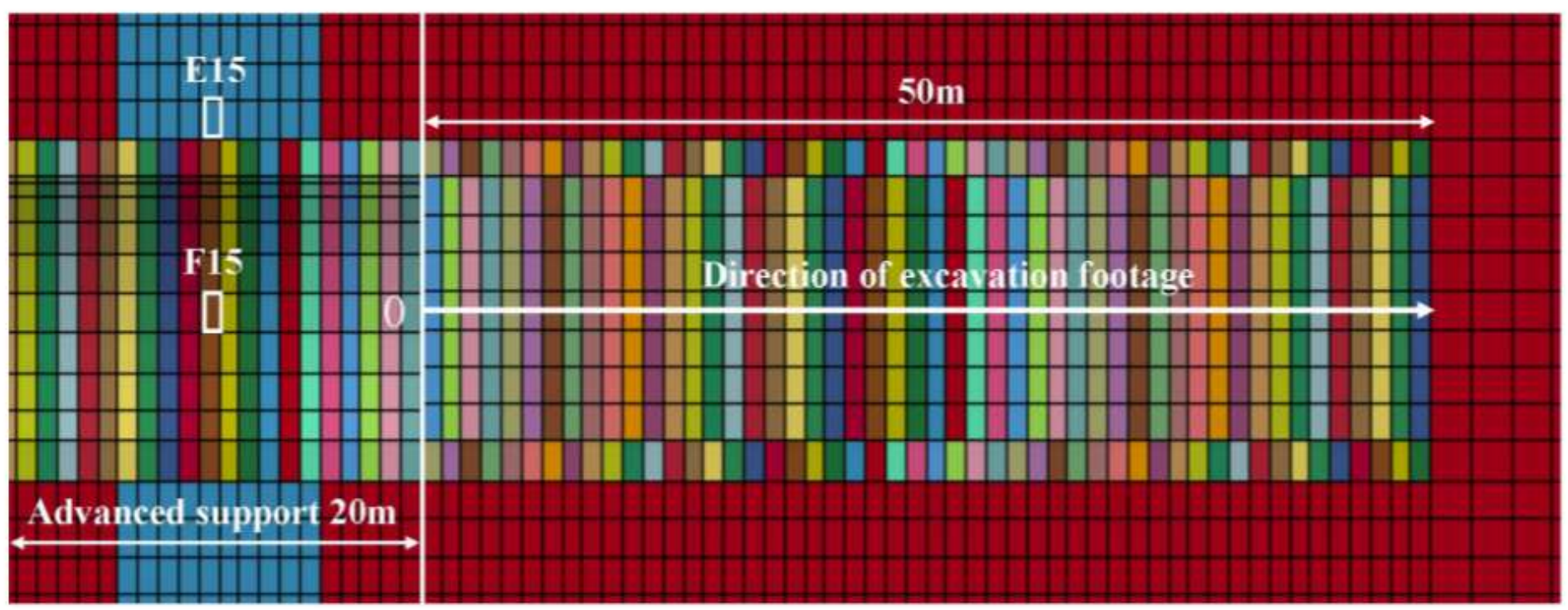

Figure 20 
Excavation of rock mass behind the fracture zone

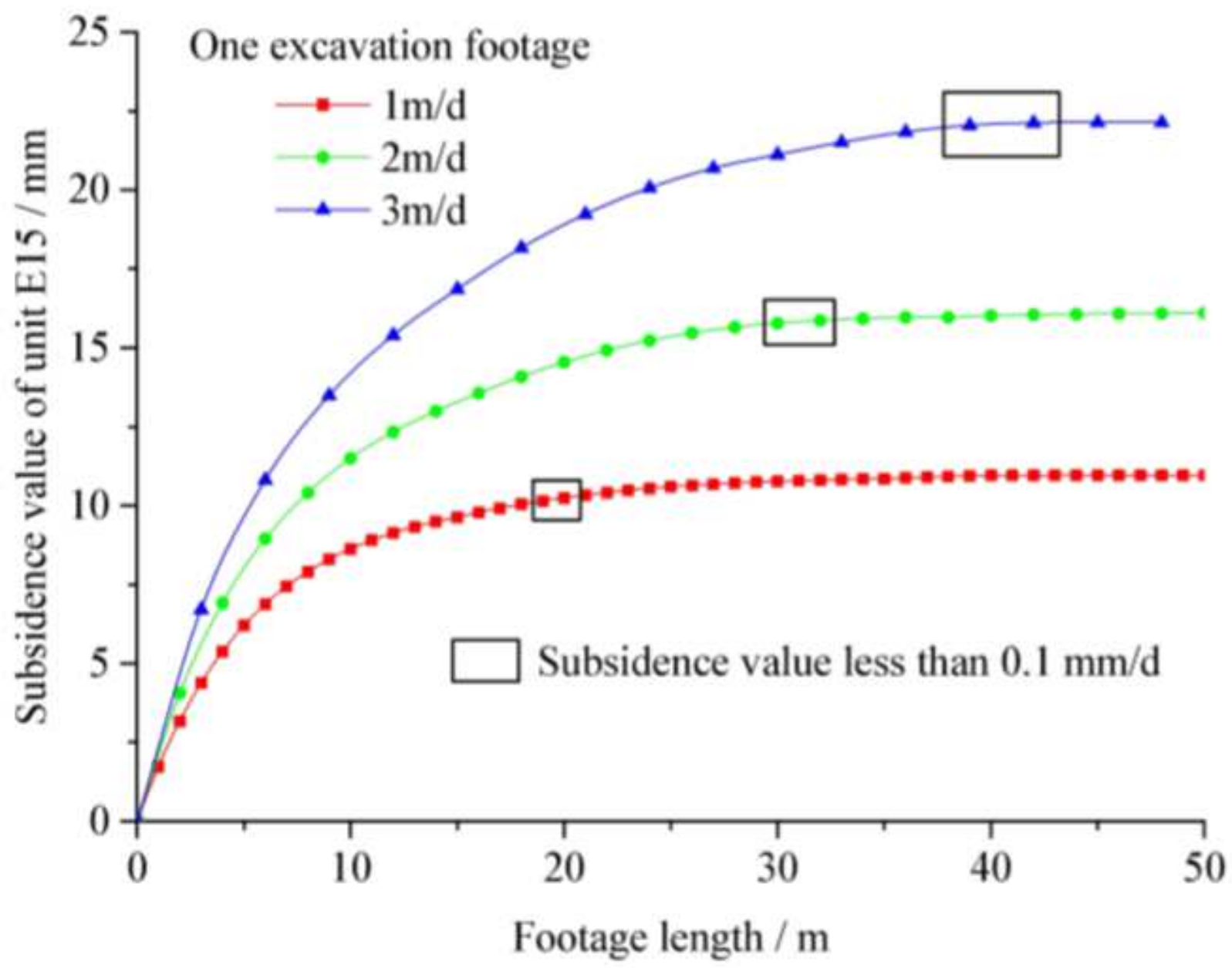

Figure 21

Calculated subsidence of surrounding rocks in the vault under different excavation footages 


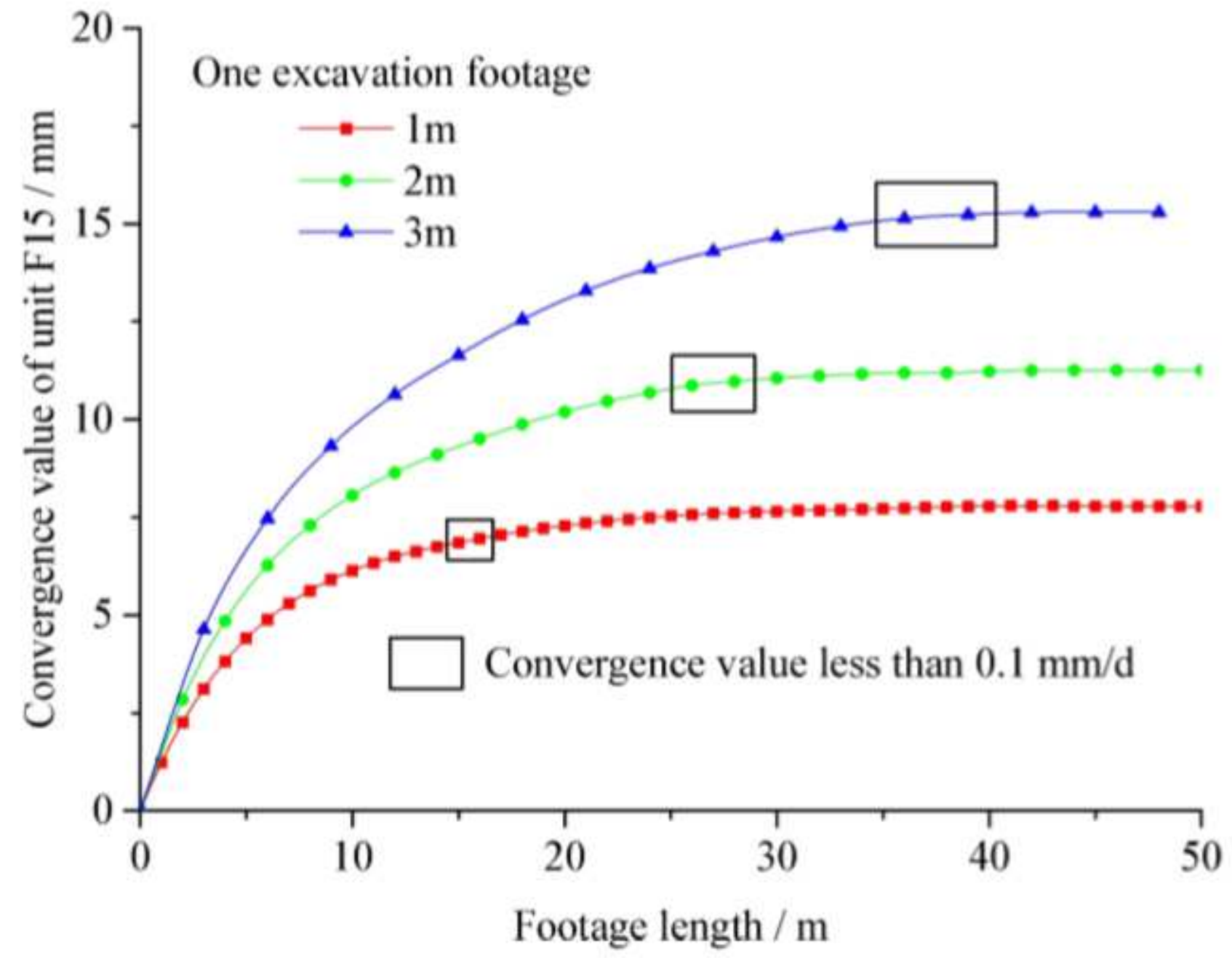

Figure 22

Calculated convergence of surrounding rocks in the sidewalls under different excavation footages 